\title{
Probing the relationship between electromagnetic ion cyclotron waves and plasmaspheric plumes near geosynchronous orbit
}

\author{
J. L. Posch, ${ }^{1}$ M. J. Engebretson, ${ }^{1}$ M. T. Murphy, ${ }^{1,2}$ M. H. Denton, ${ }^{3}$ M. R. Lessard, ${ }^{4}$ \\ and R. B. Horne ${ }^{5,6}$ \\ Received 9 March 2010; revised 15 June 2010; accepted 7 July 2010; published 11 November 2010.
}

[1] Plasmaspheric plumes created during disturbed geomagnetic conditions have been suggested as a major cause of increased occurrences of electromagnetic ion cyclotron (EMIC) waves at these times. We have catalogued occurrences of strong Pc1 EMIC waves from 1996 through 2003 at three automated geophysical observatories operated by the British Antarctic Survey at auroral zone latitudes in Antarctica $(L=6.28,7.68$, and 8.07) and have compared them to the occurrence of plasmaspheric plumes in space, using simultaneous data from the Magnetospheric Plasma Analyzer on the Los Alamos National Laboratory 1990-095 spacecraft, in geosynchronous orbit at the same magnetic longitude. A superposed epoch analysis of these data was conducted for several categories of disturbed geomagnetic conditions, including magnetic storms, high-speed streams, and storm sudden commencements. We found only a weak correspondence between the occurrence of strong Pc1 waves observed on the ground and either plasmaspheric plumes or intervals of extended plasmasphere at geosynchronous orbit before, during, or after the onset of any of these categories. Strong Pc1 activity peaked near or slightly after local noon during all storm phases, consistent with equatorial observations by the Active Magnetospheric Particle Tracer Explorers/Charge Composition Explorer satellite at these $L$ shells. The highest Pc1 occurrence probability was at or 1-2 days before storm onset and during the late recovery phase. Occurrence was lowest during the early recovery phase, consistent with the decrease in solar wind pressure often seen at this time. The peak at onset is consistent with earlier observations of waves in the outer magnetosphere stimulated by sudden impulses and magnetospheric compressions.

Citation: Posch, J. L., M. J. Engebretson, M. T. Murphy, M. H. Denton, M. R. Lessard, and R. B. Horne (2010), Probing the relationship between electromagnetic ion cyclotron waves and plasmaspheric plumes near geosynchronous orbit, J. Geophys. Res., 115, A11205, doi:10.1029/2010JA015446.

\section{Introduction}

[2] An increase in the occurrence of electromagnetic ion cyclotron (EMIC) waves in Earth's magnetosphere has long been noted during the aftermath of magnetic storms. Such waves, classified as Pc1-2 waves $(0.1-5.0 \mathrm{~Hz})$, are observed routinely in space and, also, by ground-based search coil magnetometers. These waves have been suggested in many theoretical studies as a significant loss mechanism for both ring current ions and, via parasitic interactions, radiationbelt electrons (e.g., Meredith et al. [2003] and Summers and

\footnotetext{
${ }^{1}$ Augsburg College, Minneapolis, Minnesota, USA.

${ }^{2}$ Now at Department of Civil Engineering, University of Minnesota, Minneapolis, Minnesota, USA.

${ }^{3}$ Department of Physics, Lancaster University, Lancaster, UK.

${ }^{4}$ University of New Hampshire, Durham, New Hampshire, USA.

${ }^{5}$ British Antarctic Survey, Cambridge, UK.

${ }^{6}$ Also at Department of Automatic Control and Systems Engineering, University of Sheffield, Sheffield, UK.
}

Copyright 2010 by the American Geophysical Union. 0148-0227/10/2010JA015446
Thorne [2003]; review by Thorne et al. [2005]). Recent observational studies showing a close connection between EMIC waves and precipitation of radiation-belt electrons include Clilverd et al. [2007], Sandanger et al. [2007], Miyoshi et al. [2008], and Rodger et al. [2008]. A close connection between them was also inferred by Borovsky and Denton [2009], but without direct EMIC observations.

[3] As noted by Engebretson et al. [2008a], many early studies of EMIC waves suggested that they would be preferentially excited near or just outside the plasmapause, both because of the suppression of wave refraction at the plasmapause density gradient and because of the presence of enhanced levels of cold plasma in that region. Using CRRES satellite data, however, Fraser and Nguyen [2001] found that this region was not a preferred site, but consistent with the earlier Active Magnetospheric Particle Tracer Explorers/Charge Composition Explorer (AMPTE/CCE) satellite observations of Anderson et al. [1992a, 1992b], they found that the probability of wave occurrence increased with radial distance ( $L$ shell). Their observations did, however, suggest that afternoon sector waves might be associated 


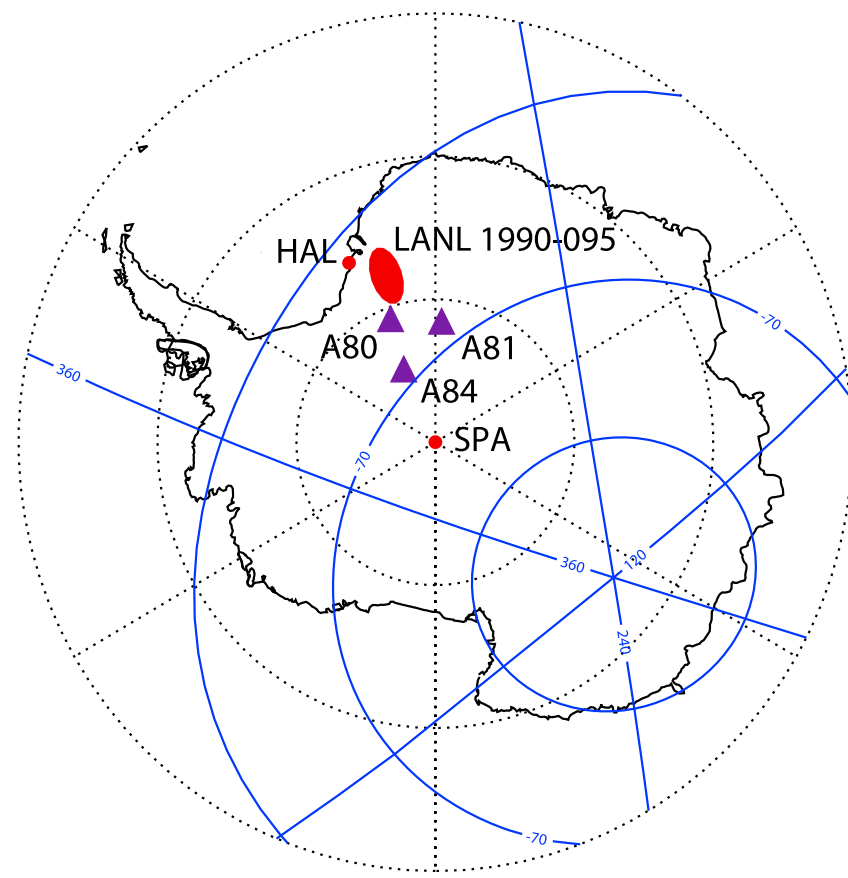

Figure 1. Map of Antarctica showing the location of British Antarctic Survey (BAS) automated geophysical observatories (AGOs) A80, A81, and A84, as well as the Southern Hemisphere footprint of the Los Alamos National Laboratory (LANL) 1990-095 spacecraft, adapted from a magnetic footpoint tracing produced using CDAWEB (http://cdaweb.gsfc.nasa.gov).

with the plasmapause bulge and, possibly, detached plasma regions. Observational support for an association was provided by Fuselier et al. [2004], Spasojevic et al. [2004], Fraser et al. [2005], and Immel et al. [2005]. Observations by the Extreme Ultraviolet (EUV) Imager on the IMAGE satellite have also revealed that what were referred to as detached plasma regions were in fact often "convection tails" or plasmaspheric plumes, regions convecting sunward but still connected to the main plasmasphere in the dusk sector [Burch et al., 2001; Sandel et al., 2001].

[4] Chen et al. [2009] showed theoretically that EMIC wave growth is expected to be strongest in three regions in the dayside magnetosphere: near the plasmapause, within regions with density structure in plumes, and in the lowdensity trough region at large $L$ values $(\geq 6.5)$. They also showed that the lowest resonant electron energies for interaction with EMIC waves (approximately a few megaelectron volts) would be found in structured plumes rather than in the low-density trough region. EMIC waves in plumes can thus resonate with radiation-belt electrons with lower energies and, thereby, cause more loss from the radiation belts than can such waves in the low-density trough. It is thus important to determine whether there is evidence of enhanced occurrence of EMIC waves in plumes during the onset or main phase of storms, when rapid radiation belt losses are at times observed [Thorne et al., 2005; Borovsky and Denton, 2008, 2009].

[5] There have been many statistical studies of EMIC wave activity over the past several decades, outlining their occurrence as a function of latitude, solar cycle, and/or storm phase. Most early ground-based reports of EMIC wave occurrence, reviewed by Engebretson et al. [2008a], focused on the recovery phase of magnetic storms and found that wave occurrence was largest several days after storm onset. An exception is the study by Bortnik et al. [2008], which surveyed EMIC waves during magnetic storm intervals from 1999 through 2006 at Parkfield, California $(L=$ 1.77). They presented a superposed epoch analysis of EMIC wave occurrence from 6 days before the storm peak (minimum $D s t$ ) to 10 days afterward. The occurrence patterns they found are contrasted with those presented here in section 6.1. In this study, similarly, we report ground-based observations of these waves at auroral-zone latitudes before, during, and after the main phase of magnetic storms observed over an 8 year period, from 1996 through 2003. We have applied the automated wave analysis technique described by Bortnik et al. [2007] to a large multiyear suite of data from search coil magnetometers deployed at automated geophysical observatories (AGOs) by the British Antarctic Survey (BAS) at auroral latitudes $(L=6-8)$ in Antarctica. Although this $L$ range is somewhat outside the location of the peak outer radiation belt fluxes, it maps to a geosynchronous orbit, where equatorial observations of EMIC waves, ion fluxes, thermal plasma, and radiation-belt electron fluxes are routinely obtained, and thus may serve to supplement these observations once the relationship between ground-based and space-based observations is established. The occurrence of Pc1 waves in this data set is compared with observations of enhanced cold plasma (an expanded plasmasphere) and plasmaspheric plumes observed by the Los Alamos National Laboratory (LANL) 1990-095 satellite, which, as Figure 1 indicates, is situated on a flux tube whose footpoint is near BAS AGO A80. This study thus provides a means to quantitatively assess the relationship between Pc1 waves and the occurrence of plasmaspheric plumes and related regions.

\section{Data Set and Analysis Procedures}

[6] The British Antarctic Survey deployed a set of three AGOs with identical instrumentation for studies of magnetospheric physics beginning in January 1996 [Dudeney et al., 1997]. Each of these AGOs included an Augsburg CollegeUniversity of New Hampshire three-axis search coil magnetometer that sampled $\mathrm{dB} / \mathrm{dt}$ twice per second [Engebretson et al., 2002], providing measurements of magnetic oscillations with frequencies up to a maximum of $1 \mathrm{~Hz}$. Although this maximum frequency means that only the lower frequency end of the Pc1 frequency range $(0.2-5.0 \mathrm{~Hz})$ can be studied using these magnetometers, both observational and theoretical studies suggest that the frequency of the vast majority of Pcl waves generated in the outer magnetosphere $(L>6)$ will be below this limit.

[7] Figure 10a of the statistical study of Pc1 waves observed by the equatorially orbiting AMPTE/CCE satellite [Anderson et al., 1992a], shows that most events observed beyond $L=6$ at all local times (LTs) were at frequencies of $\leq 1 \mathrm{~Hz}$, and Figure 9a of that same study indicates that this was, in particular, the case in the noon-to-dusk LT sector, where most EMIC waves were observed. In addition, Figure 1a of Anderson et al. [1992b] showed that nearly all of the wave events observed in the noon-to-dusk sector 
Table 1. Gyrofrequencies of $\mathrm{H}^{+}, \mathrm{He}^{+}$, and $\mathrm{O}^{+}$and Theoretical Frequency Bounds of Wave Growth (Based on Calculations by Horne and Thorne [1993]) at the Location of the Minimum B Value Along the Field Line Corresponding to Geosynchronous Orbit, Calculated Using the Tsyganenko [1989] Magnetic Field Model

\begin{tabular}{ccccccc}
\hline & MLT & $f_{\mathrm{H}}^{+}(\mathrm{Hz})$ & $f_{\mathrm{He}}^{+}(\mathrm{Hz})$ & $f_{\mathrm{O}}^{+}(\mathrm{Hz})$ & $f_{\min }=0.125 f_{\mathrm{H}}^{+}$ & $f_{\max }=0.5 f_{\mathrm{H}}^{+}$ \\
\hline$K p=1$ & 12 & 1.72 & 0.43 & 0.11 & 0.22 & 0.86 \\
& 18 & 1.44 & 0.36 & 0.08 & 0.18 & 0.72 \\
$K p=4$ & 12 & 1.71 & 0.43 & 0.11 & 0.22 & 0.86 \\
& 18 & 1.28 & 0.32 & 0.08 & 0.16 & 0.64 \\
\hline
\end{tabular}

had normalized frequencies $\left(X=f_{\text {obs }} / f_{\mathrm{H}^{+}}\right.$, where $f_{\mathrm{H}^{+}}$is the proton gyofrequency) between $X=0.1$ and $X=0.6$, with a clear gap near $X=0.25$ corresponding to $f_{\mathrm{He}^{+}}$.

[8] Consistent with these observations, calculations by Horne and Thorne [1993] for $L=5,6$, and 7 (their Figures 13 and 14) confirmed that no wave growth was possible just above each heavy-ion frequency $\left(f_{\mathrm{O}^{+}}, X=0.0625\right.$, or $f_{\mathrm{He}^{+}}$, $X=0.25$ ) and found that for $L=5$ to 7 wave power was expected to be limited to normalized frequencies between $X=0.125$ and $X=0.24$ and between $X=0.28$ and $X=0.5$, with the highest growth rates in each band nearer to $X=0.25$.

[9] Table 1 shows the ion gyrofrequencies and range of theoretically expected Pc1 waves $(X=0.125$ to 0.5$)$ at 1200 and 1800 magnetic local time (MLT) and geosynchronous orbit $(L=6.6)$ for both quiet $(K p=1)$ and disturbed $(K p=4)$ conditions, calculated using the Tsyganenko [1989] empirical magnetic field model. Table 1 shows that for both quiet and disturbed conditions at local noon, the range of EMIC wave frequencies expected to be excited near geosynchronous orbit is included in the $0.2-1.0$ frequency band. However, near dusk, especially under more disturbed conditions, the lower end of the expected emissions in the helium band will be below the $0.2 \mathrm{~Hz}$ minimum frequency included in this study. Table 1 also indicates that little, if any, wave power in the oxygen band $\left(f<f_{\mathrm{O}}^{+}\right)$will be included in this study. According to Hu and Fraser [1994], however, little oxygen-band EMIC wave activity is expected beyond the plasmapause.

[10] Further complicating this situation is the presence of ionospheric ducting, reviewed by Engebretson et al. [2008a], which means that we cannot determine whether the waves observed at these stations occurred on overhead magnetic field lines or were ducted horizontally through the ionosphere from higher or lower L shells. As a consequence we also cannot categorize waves at any given frequency as being in the helium or hydrogen band. As a result, we have simply noted the presence of strong wave activity in the 0.2 $1.0 \mathrm{~Hz}$ frequency band for the purposes of this study.

[11] Figure 1 shows the location of the three BAS AGOs, A80, A81, and A84, located between South Pole Station $(L=$ 13.66) and Halley $(L=4.56)$. Table 2 lists the geographic coordinates of the BAS AGOs (GLAT, GLON) and their magnetic coordinates (MLAT, MLON) for epochs 1996 and 2003. Table 2 also indicates the small shift in the geomagnetic coordinates of these sites during this 8 year interval.

[12] Figure 2 shows the availability of search coil magnetometer data from the three BAS AGOs from 1996 through 2003. The black boxes indicate the stations used during each year for this study. When possible (for example in January 1997), data from another station were used to fill in data missing from the selected station. During the years 1996-2003, data were available for 2648 of the possible 2922 days, for a $90.6 \%$ coverage ratio. Of the 274 missing days, data from other AGOs were used for 78 , or $28.5 \%$ of these, bringing the modified coverage ratio to $93.3 \%$.

[13] Wave events were analyzed using the automated wave detection algorithm described by Bortnik et al. [2007]. This technique involves identification of spectral peaks (power significantly above ambient noise) in each vertical slice of an FFT-based dynamic spectrogram, grouping series of spectral peaks into continuous blocks representing discrete wave events, and for each identified event, calculating wave parameters.

[14] Each $2 \mathrm{~h}$ UT interval was examined for the presence of strong narrowband Pc1 wave activity between 0.2 and $1.0 \mathrm{~Hz}$, with a duration $\geq 10 \mathrm{~min}$, and with a power $\geq 10^{-4} \mathrm{nT}^{2}-\mathrm{Hz}^{3}$ (the same power criterion used by Engebretson et al. [2008a] for search coil data obtained at Halley, Antarctica), thus ignoring relatively weak wave events. Subsequently, a database of $2 \mathrm{~h}$ intervals was created from the output of this automated process, indicating simply the presence (1) or absence (0) of Pc1 wave activity meeting the preceding criteria. All event identifications by the automated algorithm were subsequently checked by visual inspection of daily stacked $0-1 \mathrm{~Hz}$ spectrograms, available at http://space.augsburg.edu/searchcoilrequest.php. This led to removal of 94 two-hour intervals ("false-positive" broadband ULF noise events, as shown, e.g., in Figure 3 of Engebretson et al. [2008a], in close association with intervals of strong overhead electron precipitation). "False-negative" events were also identified; in such cases Pc1 events were evident in the spectrograms that were not identified by the automated algorithm. Many of these were related to contamination by broadband noise, which was added to the search coil magnetometer signals at each of the BAS AGOs under conditions of high winds and extremely low temperatures. In the case of weak contamination waves could be clearly identified visually in the spectrograms. In addition, because these high winds were often localized, in some cases of strong contamination waves were clearly visible at one of the other available AGO sites. In other cases, strong Pc1 events that were evident in the spectrograms were simply not identified by the automated algorithm. Taken together, these led to the addition of 857 two-hour intervals, leading to a total of 2325 events. Activity was highly variable, ranging from 72 two-hour intervals with waves in November 1997 to 1 such interval in April 2000.

Table 2. Geographic and Geomagnetic Coordinates of the BAS Automated Geophysical Observatories for Epochs 1996 and 2003 ${ }^{\mathrm{a}}$

\begin{tabular}{lllllccr}
\hline Station & GLAT & GLON & MLAT & MLON & Noon MLT & $L$ & Epoch \\
\hline A80 & $80.7^{\circ} \mathrm{S}$ & $20.4^{\circ} \mathrm{W}$ & $66.3^{\circ} \mathrm{S}$ & $29.1^{\circ} \mathrm{E}$ & 1446 & 6.28 & \\
A81 & $81.5^{\circ} \mathrm{S}$ & $3.0^{\circ} \mathrm{E}$ & $68.7^{\circ} \mathrm{S}$ & $36.0^{\circ} \mathrm{E}$ & 1418 & 7.68 & 1996 \\
A84 & $84.4^{\circ} \mathrm{S}$ & $23.9^{\circ} \mathrm{W}$ & $69.2^{\circ} \mathrm{S}$ & $25.1^{\circ} \mathrm{E}$ & 1505 & 8.07 & \\
& & & & & & & \\
A80 & & & $66.4^{\circ} \mathrm{S}$ & $29.3^{\circ} \mathrm{E}$ & 1446 & 6.35 & \\
A81 & & & $68.8^{\circ} \mathrm{S}$ & $36.2^{\circ} \mathrm{E}$ & 1419 & 7.76 & 2003 \\
A84 & & & $69.3^{\circ} \mathrm{S}$ & $25.2^{\circ} \mathrm{E}$ & 1505 & 8.16 & \\
\hline
\end{tabular}

${ }^{a}$ Calculated Using the modelweb Facility at NASA/Goddard Space Flight Center (http://modelweb.gsfc.nasa.gov/models/cgm/cgm.html). GLAT, geographic latitude; GLON, geographic longitude; MLAT, magnetic latitude; MLON, magnetic longitude; MLT, magnetic local time. 


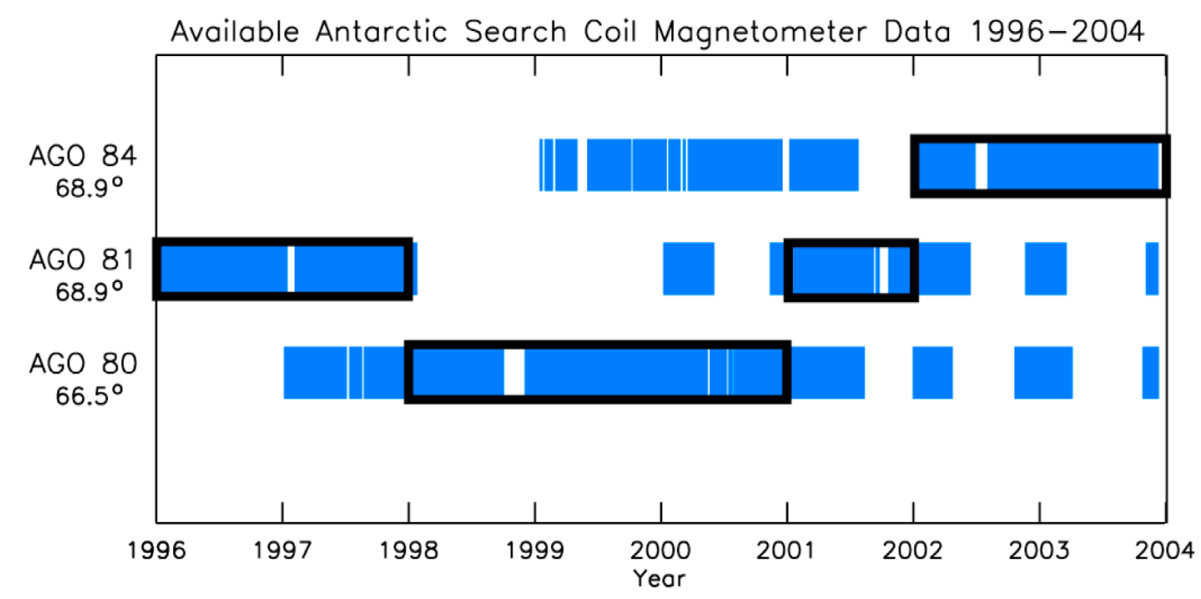

Figure 2. Diagram showing the data coverage of each of the BAS AGOs from January 1996 through December 2003. The black outline indicates the primary station used for each year.

[15] The occurrence of plasmaspheric plumes was determined for every $2 \mathrm{~h}$ interval from 1996 to 2003 using data from the MPA instrument on the LANL 1990-095 spacecraft (see Borovsky and Denton [2008] for details of plasmaspheric plume observations at geosynchronous orbit). All three of the following criteria were required for at least $10 \mathrm{~min}$ in a $2 \mathrm{~h}$ interval: (1) the cold-ion $(\sim 1-100 \mathrm{eV})$ density was between 10 and $400 \mathrm{~cm}^{-3}$; (2) the hot-ion $(\sim 0.1-45 \mathrm{keV})$ density was less than $3 \mathrm{~cm}^{-3}$ (to avoid magnetosheath intervals); and (3) the magnitude of the velocity of the cold plasma was $>12 \mathrm{~km} / \mathrm{s}$ (to exclude material that is in corotation with the Earth). Intervals of extended plasmasphere (with densities as before but with a lower velocity) were also recorded. The availability of data from the MPA instrument on the LANL 1990-095 spacecraft varied widely over the 8 year period analyzed, from 1996 to 2003 . The percentage of available data for each year is as follows: 1996, 86\%; $1997,72 \%$; 1998, 38\%; 1999, 22\%; 2000, 11\%; 2001, 33\%; $2002,80 \%$; and $2003,92 \%$.

\section{Example Events}

[16] Figures 3 and 4 show two examples of storms on the "McPherron storm list" [McPherron and Weygand, 2006] during which Pc1 waves were observed during the early stages of the main phase. These events include several cases with a clear temporal association between wave occurrence and increased solar wind pressure, but also other cases when waves were associated with plumes, or with both plumes and increased solar wind pressure, as well as cases when plumes occurred without waves. As shown later, these two storms are also typical of our data set in that waves occur predominantly in the noon-afternoon LT sector (local noon is near 1500 UT) during all storm phases.

[17] Figure 3 shows a Fourier spectrogram of the $\mathrm{Bx}$ (north-south) component of $\mathrm{dB} / \mathrm{dt}$ observed by the AGO A84 search coil magnetometer (upper plot), time-shifted solar wind dynamic pressure (in $\mathrm{nPa}$; center plot), and the SYM-H index (in nT; lower plot) during 17 and 18 August 2003. The vertical scale in the spectrogram ranges from 0 to $1 \mathrm{~Hz}(1000 \mathrm{mHz})$, and wave power is coded according to the color bar at the right. Storm onset (1700 UT on 17 August) and the end of the main phase (1500 on 18 August) are marked by vertical (red) lines. The colored insets in the center plot indicate times when plasmaspheric plumes (green) or intervals of extended plasmasphere (blue) were observed by the 1990-095 spacecraft; other times (shown in white) have data available but do not meet the criteria to be classified as plumes or plasmasphere. The solar wind dynamic pressure increased gradually from $\sim 1200$ to 1900 UT, with sharp transient increases near 1430 UT, at onset at $1700 \mathrm{UT}$, and for $1.5 \mathrm{~h}$ beginning at $1730 \mathrm{UT}$. The two more extended increases were accompanied by increases in the SYM-H index. Strong wave activity was seen during much of the interval from 1400 to 1900 UT and was especially strong during the first pressure increase, shortly before 1500 UT, and near storm onset, at 1700 UT. Waves also occurred during the second extended pressure increase. A plasmaspheric plume was detected from 1730 to 1930 UT, coincident with the third Pc1 burst, while intervals of mixed plume and extended plasmasphere were associated with part of the intense Pcl burst from 1600 to 1800 UT. No enhanced cold plasma was evident, however, during the first Pc1 burst, from 1400 to 1530 UT. Plumes and intervals of extended plasmasphere were also observed from 1330 to 1630 UT on 18 August, but during this interval no Pc1 waves were observed on the ground.

[18] Figure 4 shows similar data for the magnetic storm on 13-14 October 2003. Pc1 activity again occurred during intervals of increased solar wind dynamic pressure from 0700 to $0900 \mathrm{UT}$ on 13 October (from 5 to $3 \mathrm{~h}$ before onset), at onset (1200 UT), and late in the main phase, from 1400 to 1800 UT on 14 October. Plasmaspheric plumes were also observed during and slightly after this interval. Pc1 waves also occurred near 1500 UT and from 1600 to 1800 UT on 13 October. During the latter intervals plasmaspheric plumes and/or extended plasmasphere densities were observed at geosynchronous orbit but the solar wind pressure was decreasing.

\section{Long-Term Statistical Patterns}

[19] Figure 5a shows the occurrence rate of Pc1 events identified during each year (solid line) and the annual mean 


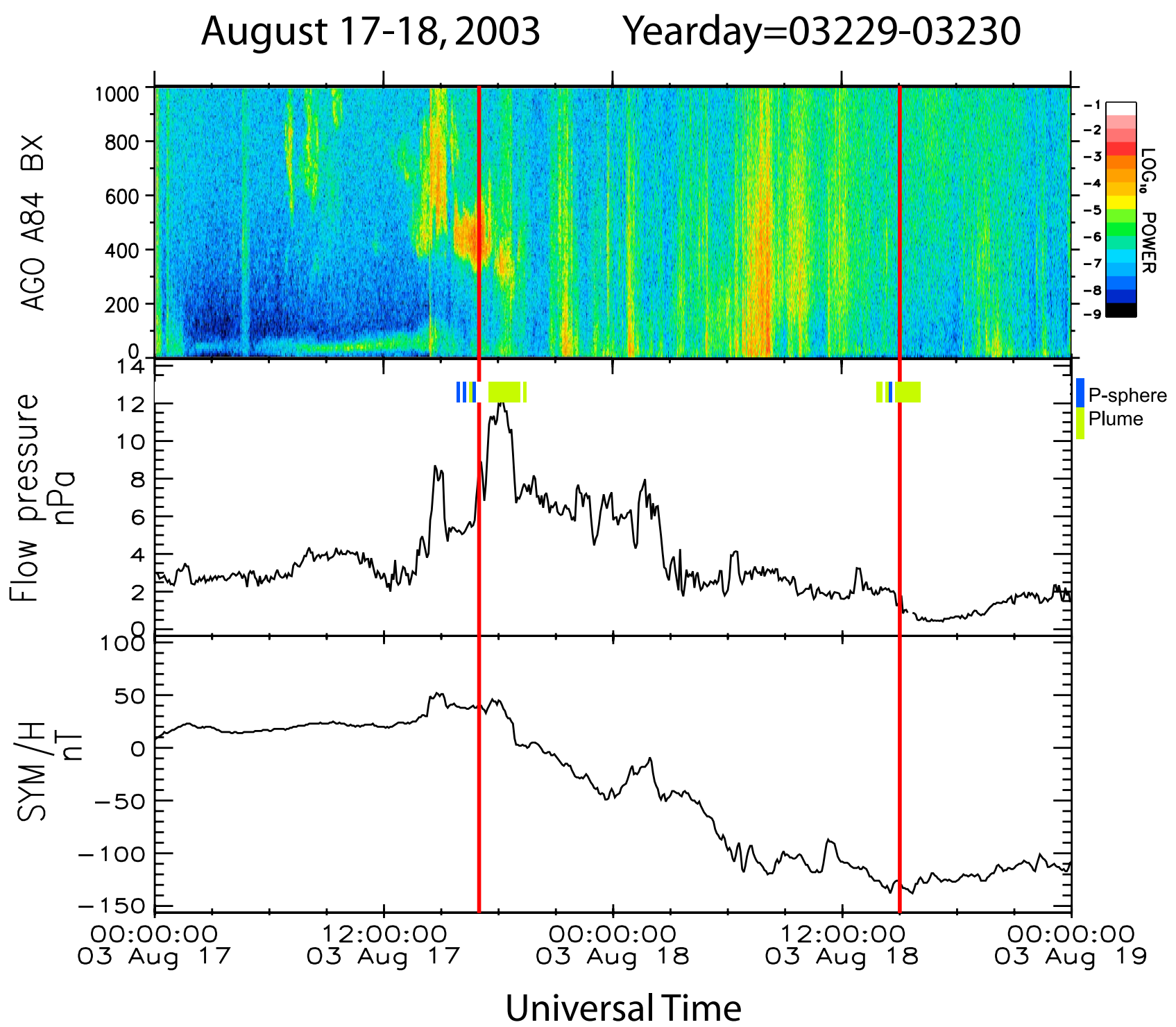

Figure 3. Fourier spectrograms of the Bx (north-south) component of magnetic field data from BAS AGO A84 for 17-18 August 2003 (upper plot), solar wind flow pressure at 1 AU (center plot; from the OMNI database at NASA/Goddard Space Flight Center), and the SYM-H index (lower plot; from the World Data Center for Geomagnetism, Kyoto, Japan). Insets in the center plot indicate times when plasmaspheric plumes (green) or nonplume plasmaspheric densities (blue) were observed at the LANL 1990-095 spacecraft.

international sunspot number (dashed line) from 1996 through 2003, obtained from the National Geophysical Data Center (http://www.ngdc.noaa.gov/stp/SOLAR/ftpsunspotnumber. $\mathrm{html}$ ). A minimum in occurrence is evident during 2000-2002, corresponding to solar maximum. The anticorrelation between Pc1 occurrence and sunspot activity is well known [e.g., Mursula et al., 1994, 1996; Kangas et al., 1998] and is often attributed to an increase in $\mathrm{O}^{+}$levels in the magnetosphere during solar maximum conditions.

[20] Figure $5 \mathrm{~b}$ shows the occurrence rate of plasmaspheric plume occurrences (solid line) and of extended plasmasphere occurrences (high density but lower velocity; dashed line) at the LANL 1990-095 spacecraft during this same 8 year interval. The minimum in occurrence of plumes and plasmaspheric intervals in 2000 coincides with the beginning of a 3 year minimum in Pcl wave occurrence, but overall the yearly Pcl and plume/plasmaspheric density trends do not show good agreement.

[21] The diurnal/LT dependences of Pc1 wave events and plume/extended plasmasphere occurrences for the combined 8 year data set are shown in Figures $6 a-6 c$ and the patterns for individual years are shown in Figures $6 \mathrm{~d}-6 \mathrm{f}$. The combined 8 year diurnal distribution of Pc1 events (Figure 6a) shows an extended nighttime minimum, a prenoon rise, and a peak $2 \mathrm{~h}$ after local noon (at $1700 \mathrm{UT}$ ). The corresponding 8 year diurnal distribution of plume occurrences and extended plasmasphere occurrences (Figures $6 b$ and $6 c$ ) is shifted roughly $2 \mathrm{~h}$ later, peaking at $1900 \mathrm{UT}$. 


\section{October 13-14, $2003 \quad$ Yearday=03286-03287}

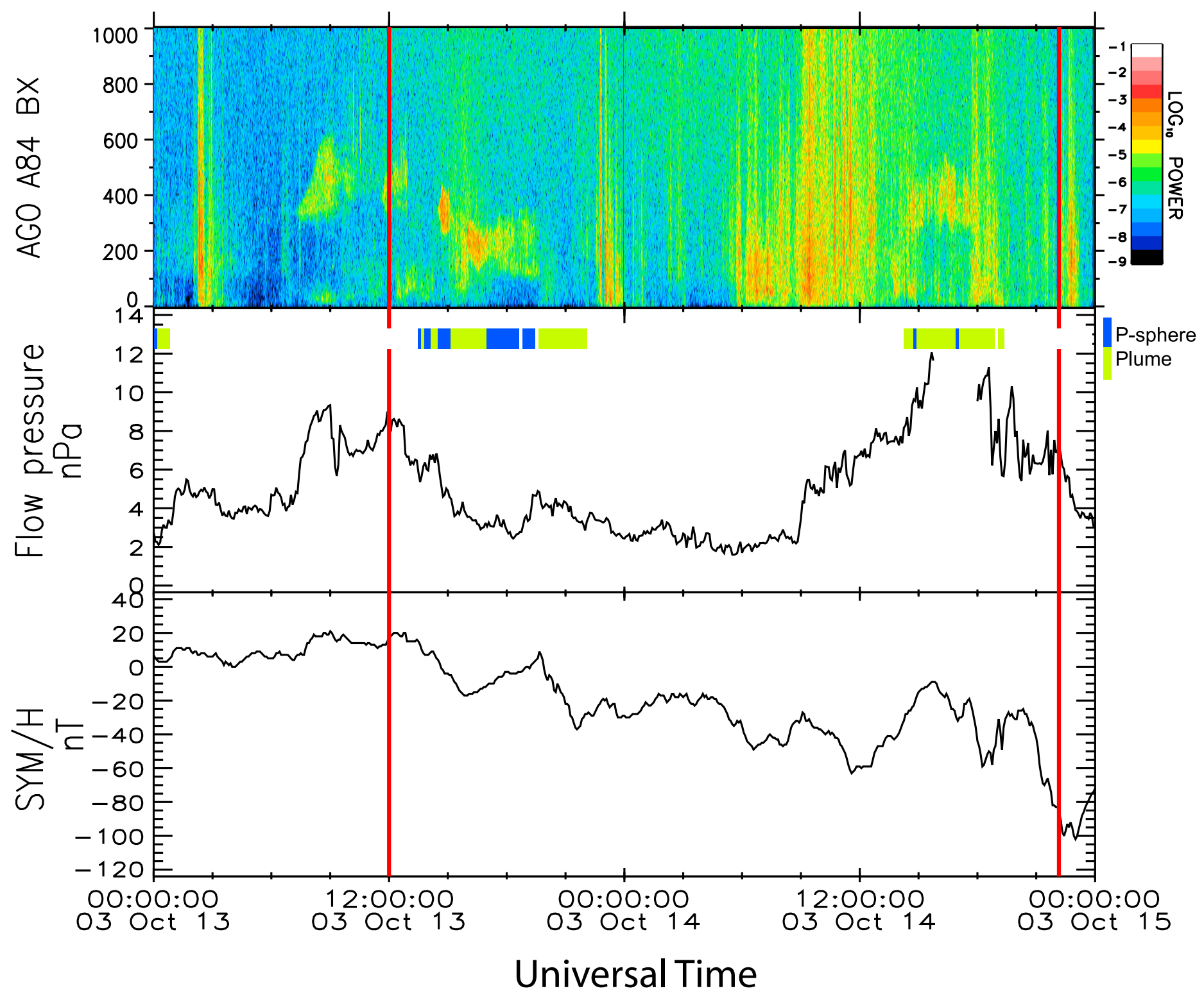

Figure 4. Fourier spectrograms of the Bx (north-south) component of magnetic field data from BAS AGO A84 for 13-14 October 2003 (upper plot), solar wind flow pressure at 1 AU (center plot), and the SYM-H index (lower plot), as in Figure 3. Insets in the center plot indicate times when plasmaspheric plumes (green) or nonplume plasmaspheric densities (blue) were observed at the LANL 1990-095 spacecraft.

[22] The yearly diurnal distributions of Pc1 wave events (Figure 6d) indicate little deviation from the aggregate pattern. The yearly diurnal distributions of plume occurrences (Figure 6e) and extended plasmasphere occurrences (Figure 6f) exhibit somewhat greater variations and, again, demonstrate that their yearly diurnal distributions do not match the yearly diurnal distributions of Pcl wave events.

[23] Both the diurnal variations and the solar cycle variations shown in Figures 5a, 6a, and 6d are consistent with earlier satellite observations of equatorial Pc1 activity by AMPTE/CCE in the $L=6-7$ range during two intervals of low and high solar activity, respectively [Mursula et al., 1996, Figure 1].

\section{Superposed Epoch Analyses}

[24] In this section we present superposed epoch plots of the occurrence of Pc1 waves, plasmaspheric plumes, and extended plasmaphere intervals for geomagnetic storms, storm sudden commencements (SSCs), and high-speed streams (HSSs). Each plot shows a color-coded grid of fractional occurrence as a function of UT (vertical axis) in $2 \mathrm{~h}$ bins. The horizontal axis shows either daily occurrence 

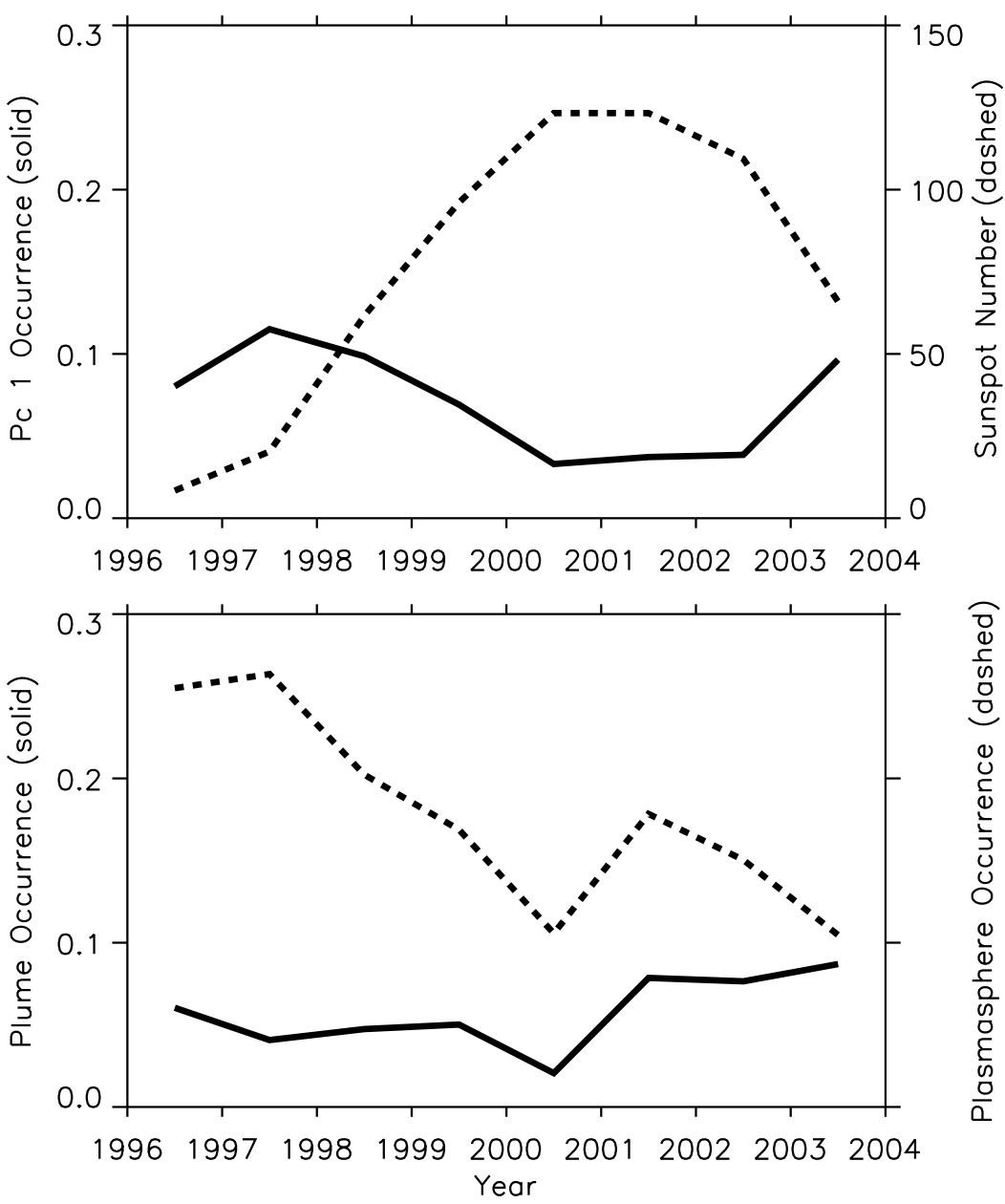

Figure 5. (a) Occurrence rate of strong Pcl events (occurrences during a $2 \mathrm{~h}$ UT interval) identified during each year (solid line) and the annual mean international sunspot number (dashed line) from 1996 through 2003. (b) Occurrence rate of plasmaspheric plumes (solid line) and nonplume plasmasphere occurrences (dashed line) during 2 h UT intervals at the LANL 1990-095 spacecraft from 1996 through 2003.

rates during a 16 day interval, from 6 days before to 10 days after the day of zero epoch, or occurrence rates during $2 \mathrm{~h}$ intervals, from $48 \mathrm{~h}$ before to $72 \mathrm{~h}$ after the hour of zero epoch. Local noon $(\sim 1500 \mathrm{UT})$ is indicated by a horizontal white line, and the zero epoch is indicated by a vertical red line. Both the start time and the end time of the main phase are included in the McPherron storm list [McPherron and Weygand, 2006], and plots are shown using both as zero epoch times. For SSC events it is the time of SSC occurrence, and for HSSs it is the time of the onset of enhanced convection.

\subsection{Geomagnetic Storms}

[25] We begin with the subset of 133 magnetic storms occurring between 1996 and 2003 of the 154-storm McPherron list [McPherron and Weygand, 2006] for which we had full magnetic field data coverage. The plume/ plasmasphere coverage was $46 \%$ for these events, which we consider sufficient for comparison to Pc1 occurrences. This list includes the times of both the onset and the end of the main phase, and the large number of events in this data set also provides sufficient statistical coverage to allow binning the data in $2 \mathrm{~h}$ intervals. This allows us to provide a statistical characterization of occurrence at higher time resolution shortly before onset, during the brief onset phase [Kangas et al., 1998], during the main phase, and during the early recovery phase. Because the duration of the main phase of magnetic storms can vary from $1-2 \mathrm{~h}$ to well over 1 day, separate displays are needed to show the occurrence of waves, plumes, and plasmaspheric densities relative to storm onset and relative to the end of main phase (the time of minimum Dst).

[26] Superposed epoch plots show the occurrence of waves, plumes, and extended plasmasphere during these storms relative to the day of onset (Figures $7 \mathrm{a}-7 \mathrm{c}$ ) and relative to the day of minimum Dst (Figures $7 \mathrm{~d}-7 \mathrm{f}$ ). The Pc1 occurrence rate (Figures $7 \mathrm{a}$ and $7 \mathrm{~d}$ ) exceeded $10 \%$ only between 1400 and 2000 UT (between 1100 and 1700 MLT), with peak occurrence rates even narrower in LT during all storm phases (between 1600 and 1800 UT and 1300 and $1500 \mathrm{MLT})$. Occurrence frequencies during the later recovery phase were comparable to pre-storm levels during these LT intervals. Figures $7 \mathrm{a}$ and $7 \mathrm{~d}$ also show a near-total dropout of Pc1 wave activity between 2200 and 1400 UT 

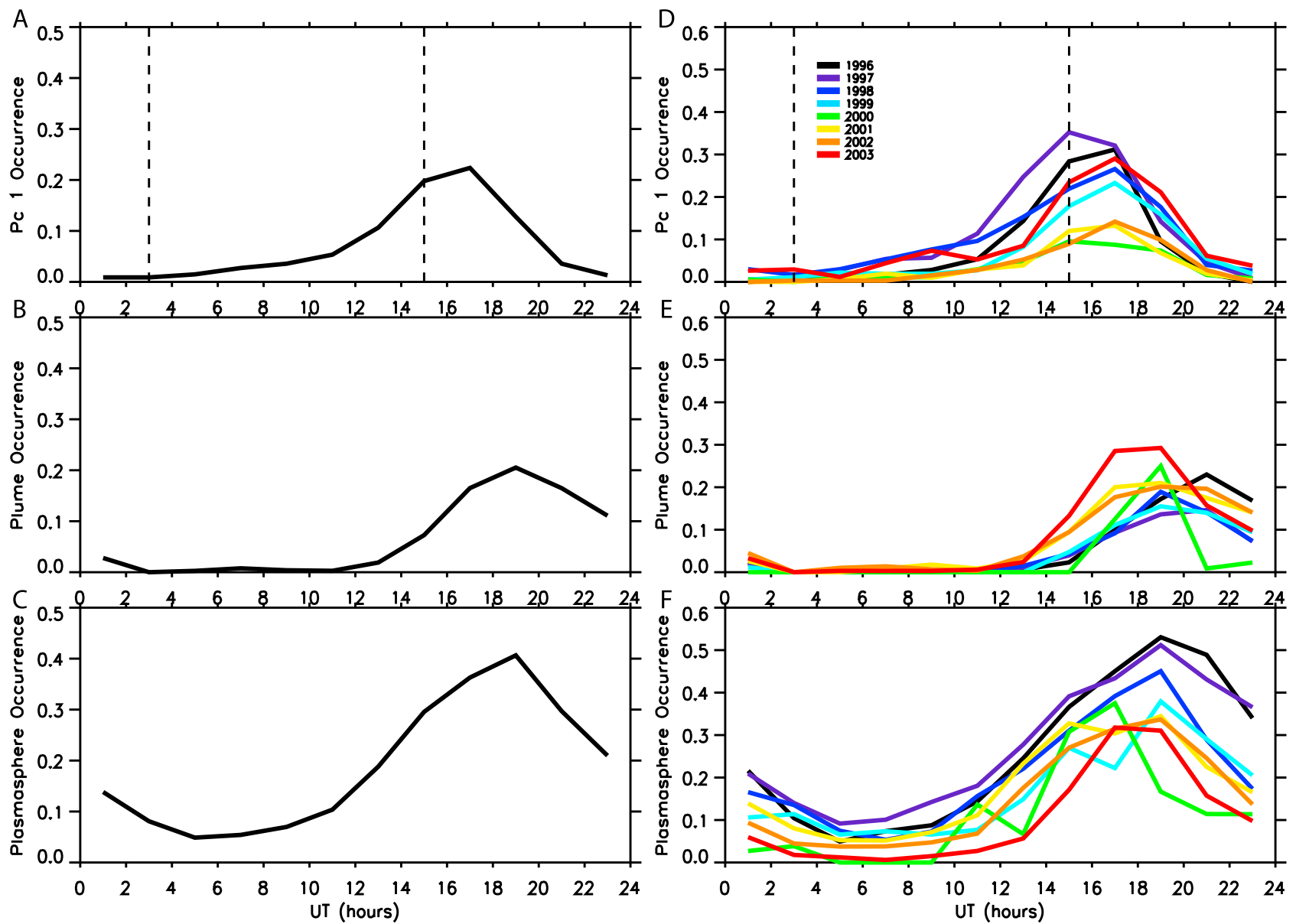

Figure 6. Local time occurrence distributions during 2 h UT intervals from 1996 through 2003 of (a) strong Pc1 events, (b) plasmaspheric plumes, and (c) nonplume plasmaspheric events. (d-f) Local time distributions of these same quantities, respectively, for each individual year. Dashed vertical lines in the upper plots indicate local midnight (0300 UT) and local noon (1500 UT) at the BAS AGOs, respectively.

(1900-0900 MLT) during the initial 2 days of the recovery phase.

[27] Comparison of these plots near epoch 0 shows that waves occurred rather frequently during local noon/early afternoon hours on the day of onset (with the same UT/LT range and occurrence pattern as for prestorm days), but much less frequently after the end of the main phase. However, the 1 day time steps used in Figure 7 cannot adequately characterize these occurrence patterns. Figure 8 , in a similar format but with time incremented in $2 \mathrm{~h}$ blocks, shows occurrence rates from $48 \mathrm{~h}$ before to $72 \mathrm{~h}$ after the beginning and end of the main phase, respectively. Figures $8 \mathrm{~b}$, $8 \mathrm{c}, 8 \mathrm{e}$, and $8 \mathrm{f}$ have a small number of time bins where no data were available (shown in gray).

[28] Figure 8a, for which the zero epoch is the start time of the main phase (with $2 \mathrm{~h}$ time resolution), shows that $\mathrm{Pc} 1$ waves occurred at rates similar to or even slightly lower than pre-storm values for $\sim 8 \mathrm{~h}$ after onset in the dayside 1400 2000 UT region (1100-1700 MLT) but dropped out within $2 \mathrm{~h}$ after onset at nearly all other LTs. The UT/MLT sector with the highest main phase occurrence rate was again 1600-1800 UT (1300-1500 LT).
[29] Figure 8d, for which the zero epoch is the end of the main phase, shows a gradual and moderate decrease in wave occurrence in the noon-postnoon LT sector during the transition from the end of the main phase through the first $\sim 6 \mathrm{~h}$ of the recovery phase and, again, essentially no wave activity during this period at other LTs. Occurrence was lowest from 6 to $20 \mathrm{~h}$ after minimum Dst and increased gradually at all LTs beginning roughly $24 \mathrm{~h}$ after minimum Dst and $36 \mathrm{~h}$ after onset.

[30] The occurrence of plumes and extended plasmaspheric densities during these storm intervals is shown using similar plots in Figures 7 and 8 . Figure $7 \mathrm{~b}$ shows a strongly increased occurrence of plumes between 1400 and 2000 UT (1100 to 1700 LT) on the day of onset, which diminished gradually over the following 2 days. On the scale of days this increase coincided with the last day of increased Pc1 activity in Figure 7 a but extended 2 days after the sudden drop in Pc1 activity. A similar time delay is evident between Figure $7 \mathrm{~d}$ and Figure $7 \mathrm{e}$. The LT pattern during prestorm and later recovery days peaked between 1600 and 2400 UT (1300 and 2100 MLT).

[31] Figures $8 \mathrm{~b}$ and $8 \mathrm{e}$ show plume occurrence on a finer time scale. Figure $8 \mathrm{~b}$ reveals the highest occurrence of 

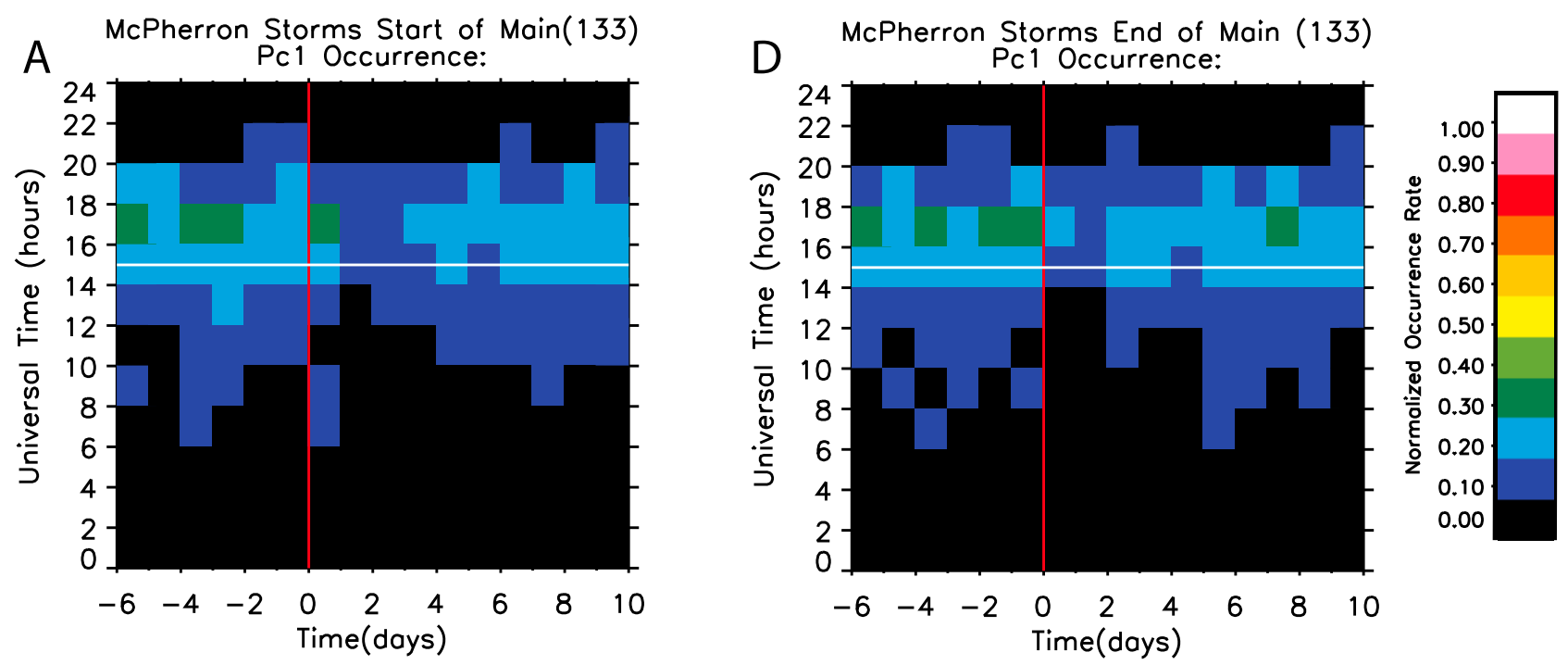

\section{B}

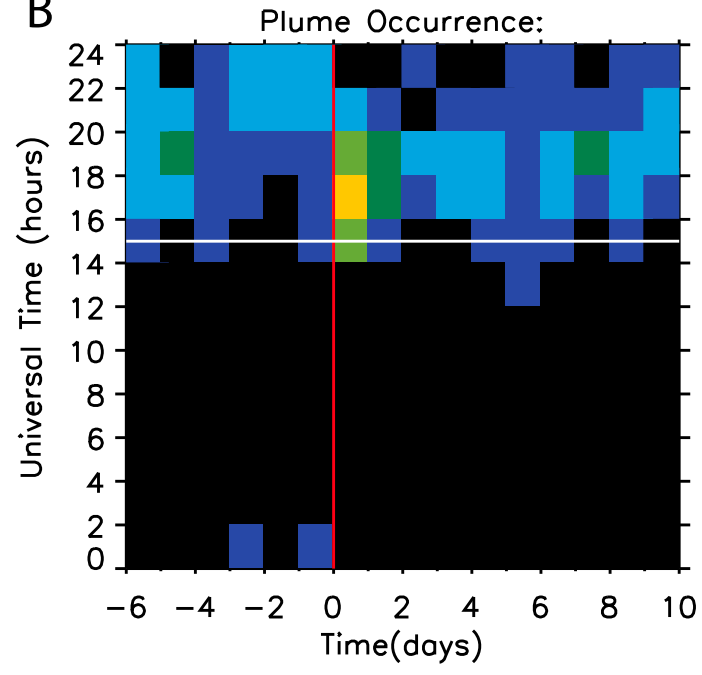

C

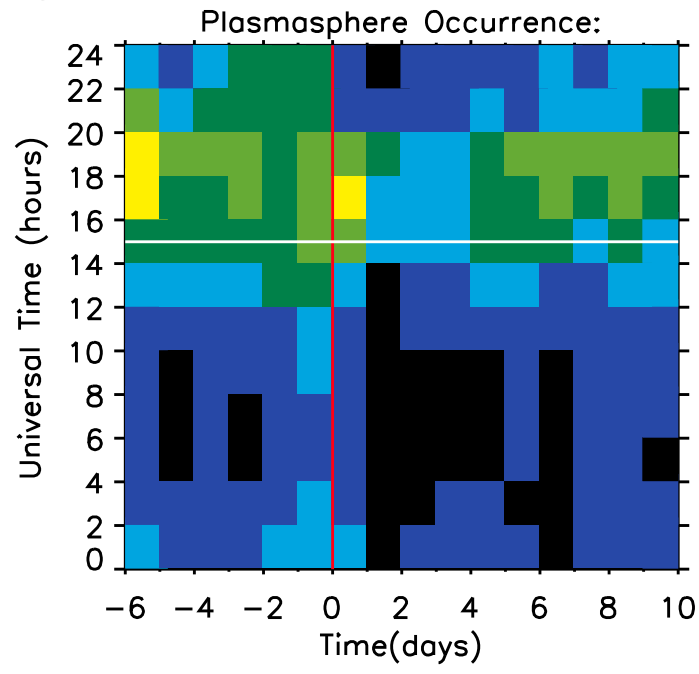

E

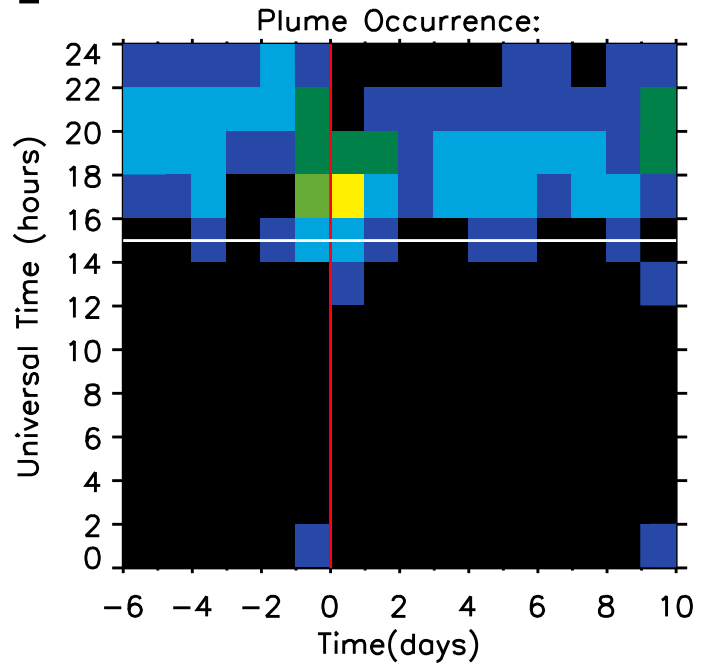

F

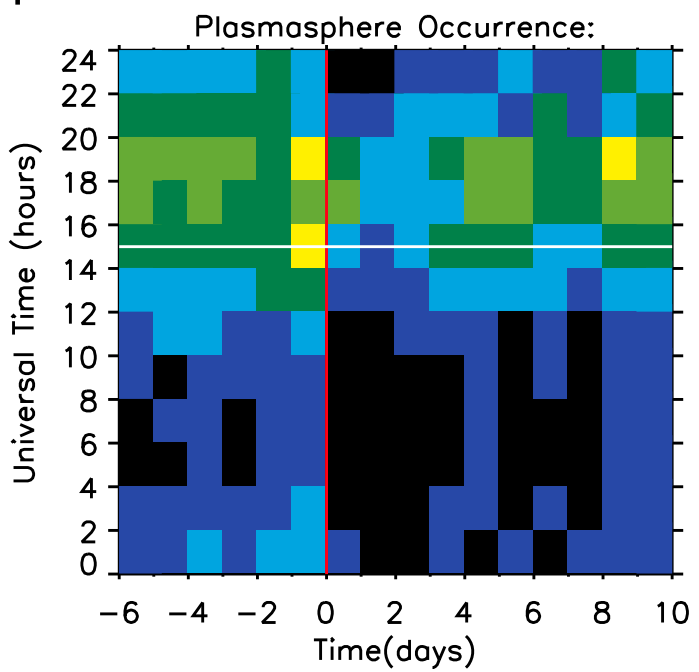

Figure 7. Superposed epoch plots of Pc1 events, plasmaspheric plumes, and nonplume plasmasphere occurrences for 133 magnetic storms on the "McPherron List" [McPherron and Weygand, 2006] from 1996 through 2003. Timing is in 1 day intervals relative to the beginning of the day of storm onset (a-c) and of the day of minimum Dst $(\mathrm{d}-\mathrm{f})$. 
A McPherron Storms Start of Main(133) Pc1 Occurrence:
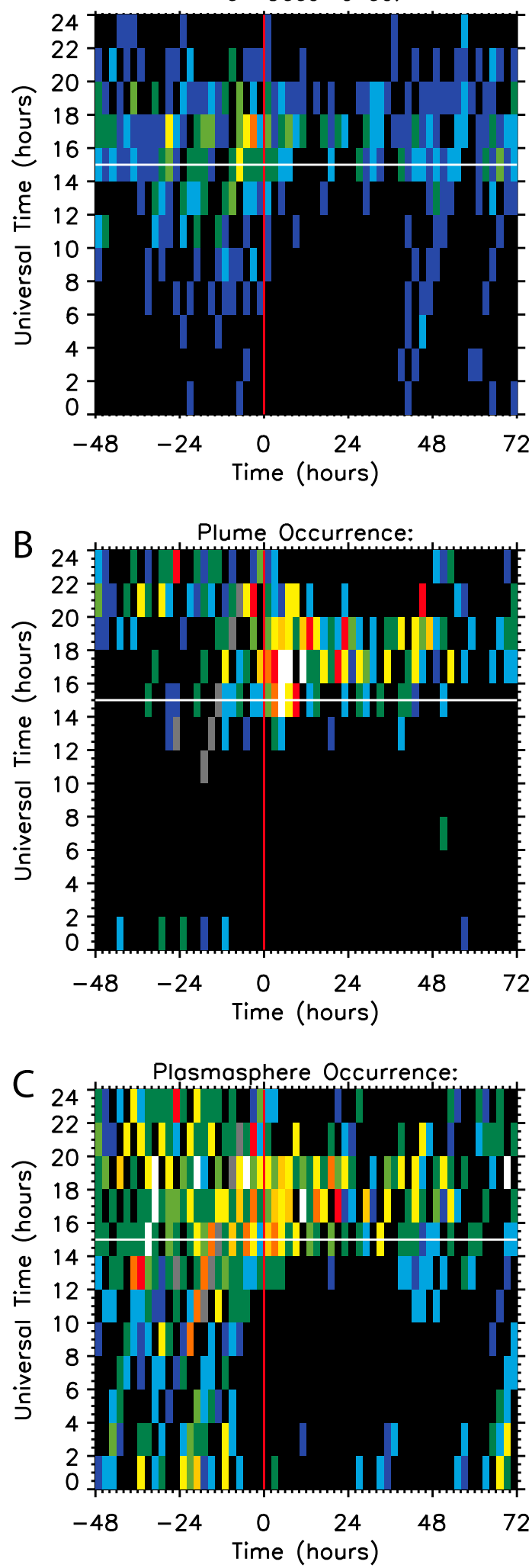

D McPherron Storms End of Main (133) Pc1 Occurrence:
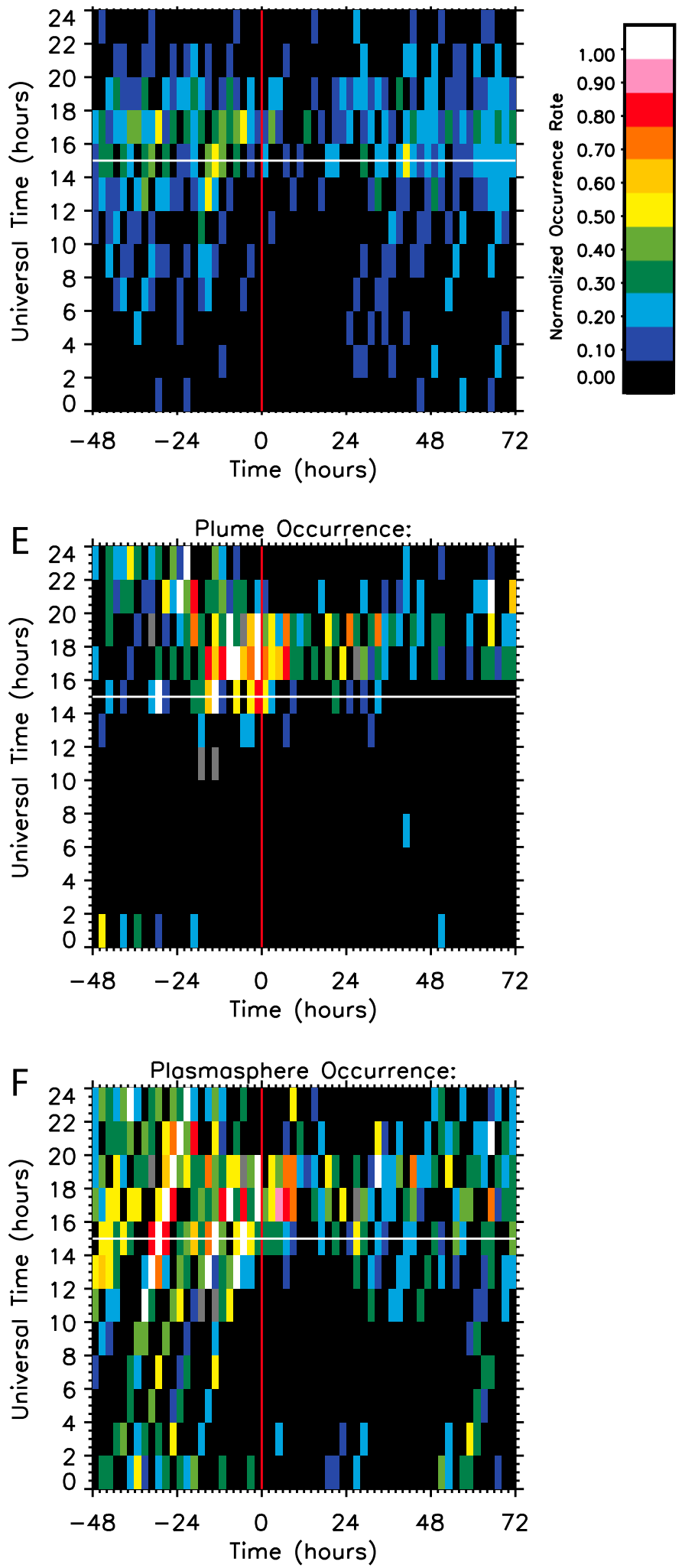

Figure 8. Superposed epoch plots of Pc1 events, plasmaspheric plumes, and nonplume plasmasphere occurrences for 133 magnetic storms on the "McPherron List" [McPherron and Weygand, 2006] from 1996 through 2003 but showing $2 \mathrm{~h}$ intervals from $48 \mathrm{~h}$ before to $72 \mathrm{~h}$ after the beginning of storm onset $(\mathrm{a}-\mathrm{c})$ and the time of minimum $\operatorname{Dst}(\mathrm{d}-\mathrm{f})$. 

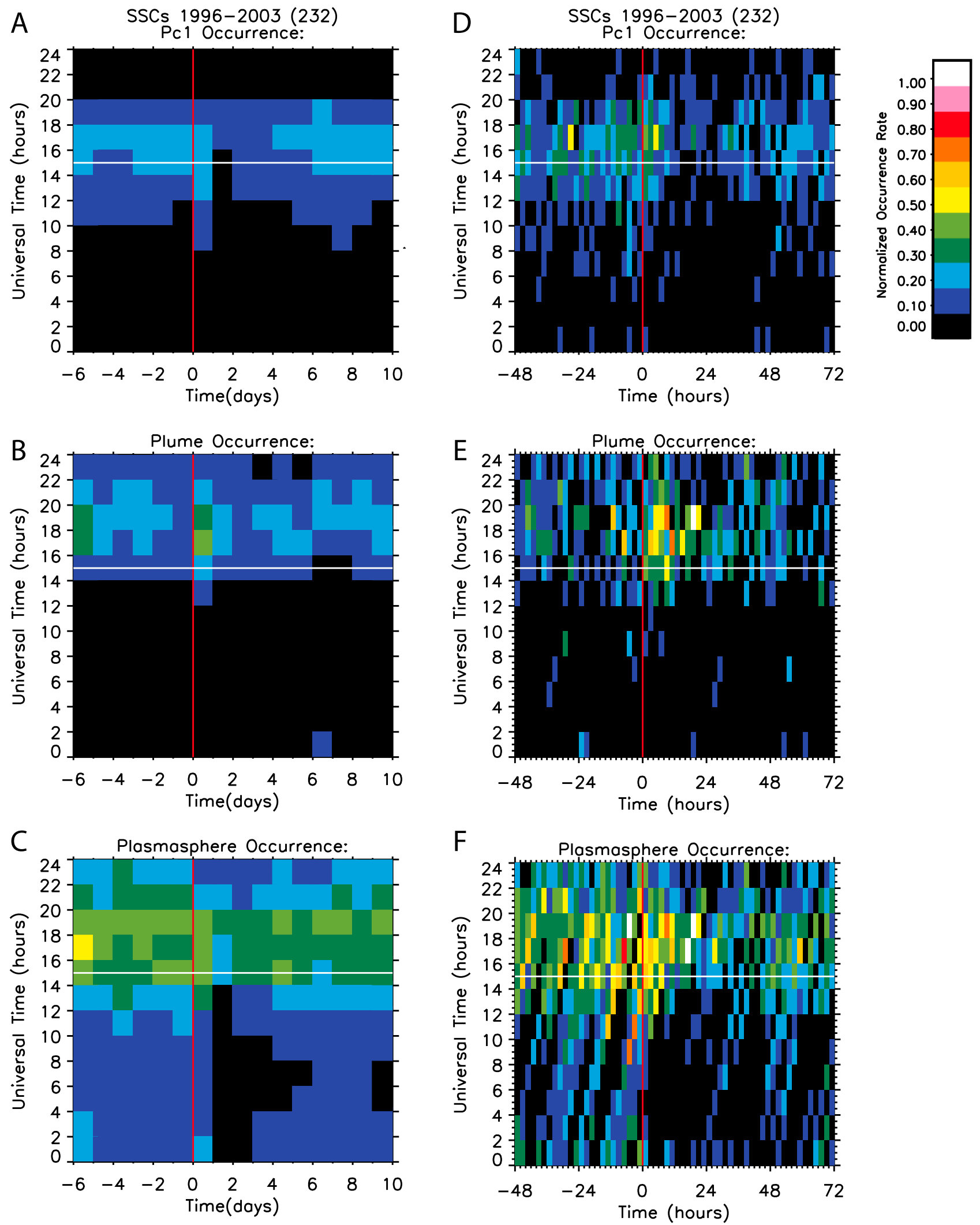

Figure 9. Superposed epoch plot of of Pcl events, plasmaspheric plumes, and nonplume plasmasphere occurrences for storm sudden commencement (SSC) intervals identified on the NOAA list from 1996 through 2003. (a-c) Timing is in 1 day intervals relative to the beginning of the day of SSC occurrence. $(\mathrm{d}-\mathrm{f})$ Timing is in $2 \mathrm{~h}$ intervals relative to the hour of SSC occurrence. 

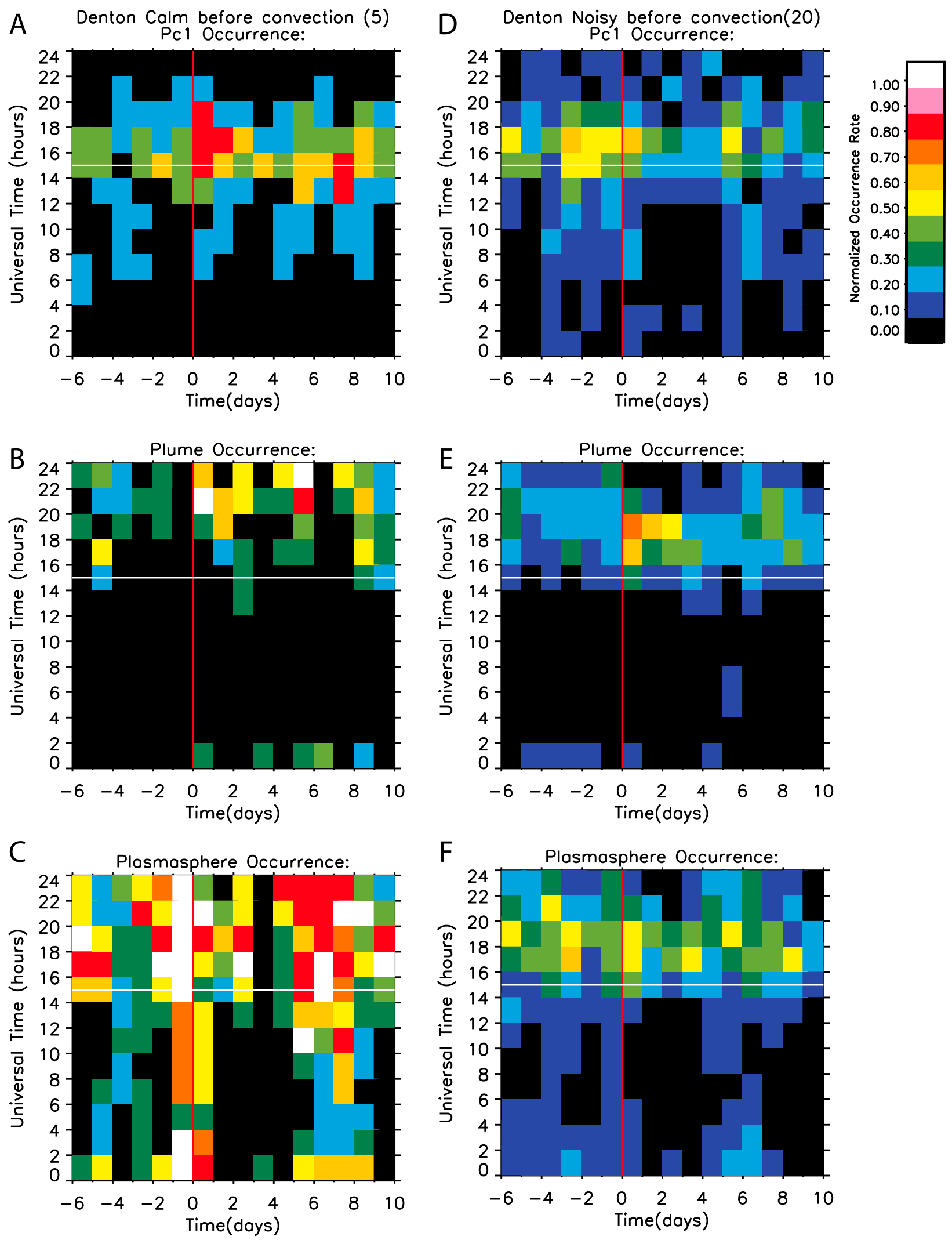

Figure 10. Superposed epoch plots of Pcl events, plasmaspheric plumes, and nonplume plasmasphere occurrences for high-speed solar wind stream (HSS) events impacting Earth's magnetosphere between 1996 and 2003 (using the criteria outlined by Denton and Borovsky [2008]). (a-c) HSS events characterized by calm before convection onset; $(\mathrm{d}-\mathrm{f}) \mathrm{HSS}$ events characterized by disturbed conditions before convection onset. Timing is relative to the beginning of the onset of convection, in 1 day intervals. 
plumes during the first $12 \mathrm{~h}$ of storm onset, with a gradual decay over the rest of the first full day, and Figure 8e shows moderately enhanced plume activity for roughly $16 \mathrm{~h}$ before and $8 \mathrm{~h}$ after the end of main phase.

[32] Occurrence patterns for an extended plasmasphere are shown in Figures 7c, 7f, 8c, and 8f. Their temporal dependence was similar to that of plumes, with occurrence peaking on the day of onset (Figure 7c) at between 1400 and 2000 UT, dropping off during the next day, and with the LT of occurrence peaking between 1400 and 2000 UT (1100 and 1700 MLT). Overall daily occurrence levels were lowest during the first to third days of the recovery phase; higher occurrence rates with similar UT dependence are evident prior to onset and during the middle to late recovery phase (after 3 days). Similar plots with $2 \mathrm{~h}$ resolution (Figures $8 \mathrm{c}$ and 8f) show that occurrences of intervals of enhanced cold plasma increased in the noon-to-dusk sector before storm onset and continued throughout the main phase and $\sim 10 \mathrm{~h}$ into the recovery phase.

[33] It is notable in Figure 8, however, that although activity was maximized in the afternoon sector in all plots (Pc1 waves, plumes, and enhanced cold-plasma densities), the detailed correlation between Pc1 waves and plumes/cold plasma in both UT and LT was poor. The peak in Pc1 activity did not coincide with maxima in plume occurrence and did not persist as long into the main and recovery phases as the plumes did. Pcl activity was highest during the $\sim 8 \mathrm{~h}$ prior to storm onset, decreased after onset, and was at its lowest levels from $\sim 6$ to $\sim 24 \mathrm{~h}$ after the end of the main phase (Figure 8d). In contrast, increased levels of plume occurrence appeared only at storm onset (Figure 8b) and extended beyond the end of main phase before declining slightly.

\subsection{Storm Sudden Commencements}

[34] Figure 9a, based on observations during 232 SSC events in the NOAA list (www.ngdc.noaa.gov/stp/SOLAR/ ftpSSC.html) during 1996 through 2003 for which 91\% of magnetic field data and $46 \%$ of plume/plasmasphere were available, shows that wave activity was again consistently highest between 1200 and 2000 UT (0900-1700 LT), with the highest occurrence rates prior to the SSC, on the day of the SSC, and 6 to 9 days later. Although SSCs do not necessarily lead to magnetic storms, the increased Pc1 occurrence on days 6-9 is consistent with most SSCs being associated with storms.

[35] Plotting the data in more temporal detail (Figure 9d) shows that, as expected, Pc1 activity was enhanced on the dayside during the first $4 \mathrm{~h}$ of SSC occurrence, but wave activity also extended for up to $\sim 8 \mathrm{~h}$ after the SSC near and shortly after local noon before decreasing to a significantly lower level during the subsequent half-day. Wave activity at other LTs was again almost entirely suppressed for the first $48 \mathrm{~h}$.

[36] Plume occurrences exhibited a clear increase on the day of SSC between 1600 and 1800 UT (Figure 9b), and a drop in occurrence at noon-to-dusk LTs over the next 2 days, and showed only a modest correlation with Pc1 events during the remainder of the 16 day interval shown. When displayed in finer temporal detail (Figure 9e), plume occurrence showed little temporal agreement with Pc1 events (Figure 9d) during the first few hours: Pc1 activity decreased after $6 \mathrm{~h}$, while plume occurrence increased gradually for $\sim 10 \mathrm{~h}$ after onset, and was mostly at later LTs. Intervals of extended plasmasphere (Figure 9f) matched the distribution of plumes much better than that of Pc1 waves.

\subsection{High-Speed Streams}

[37] Following the work of Denton and Borovksy [2008], who noted that magnetic storms driven by high-speed solar wind streams are not generally associated with large $D s t$ signatures, we also performed a superposed epoch analysis on a set of HSS events occurring between 1996 and 2003 (see Denton and Borovsky [2008] for the criteria used to determine these events). The zero epoch of these events is the onset of enhanced convection that accompanies the HSS arrival (as determined by $K p$ and the Midnight Boundary Index).

[38] Figure 10 shows occurrence distributions for the two categories of high-speed solar wind stream events identified by Denton and Borovsky [2008]: events during which the magnetosphere was calm before convection onset (Figures 10a-10c) and events during which it was disturbed (Figures 10d-10f). For both the 5 "calm before convection" and the 20 "noisy before convection" events, there was full coverage of magnetic field data and $80 \%$ and $88 \%$ coverage of plume and plasmasphere data, respectively. A "full" highly dense plasmasphere is more likely to occur during extended calm periods, while a less dense plasmasphere may be expected following disturbed conditions prior to onset. Both event categories are characterized by high wave occurrence probabilities, again mostly near noon: that is, the occurrence levels of Pc1 waves, periods of extended plasmasphere, and occurrence of plasmaspheric plumes were all significantly more elevated for the HSS events compared to other categories of events.

[39] The Pc1 occurrence rate was especially enhanced during the first 2-3 days of magnetospheric activity after calm periods (Figure 10a) but was higher during most days of the recovery phase than before HSS impact. Comparison of Figures 10a-10c shows that Pc1 wave occurrence and plume occurrence both increased sharply at the onset of convection, but at different LTs. Overall, there was consistently poor correlation both in day and in LT among Pc1 waves, plumes, and intervals of extended plasmasphere for these HSS intervals.

[40] The Pc1 occurrence rate shown in Figure 10d for HSS events preceded by disturbed conditions exhibited its highest values during this prior noise interval and on the first day of convection, then decreased. This distribution is, again, in poor agreement with that of plumes and intervals of extended plasmasphere, both of which showed quite different temporal patterns and showed occurrence maxima at later LTs.

\subsection{Summary of Superposed Epoch Observations}

[41] Pc1 waves observed at ground stations at auroral zone latitudes occurred predominantly during noon-postnoon hours during all phases of magnetic storms, SSCs, and HSS impacts. In addition, there was only a small difference between prestorm and poststorm diurnal patterns in the magnetic storm data sets presented here, but a near-total dropout on the nightside during the early recovery phase of magnetic storms (and in the aftermath of SSCs). A similar 


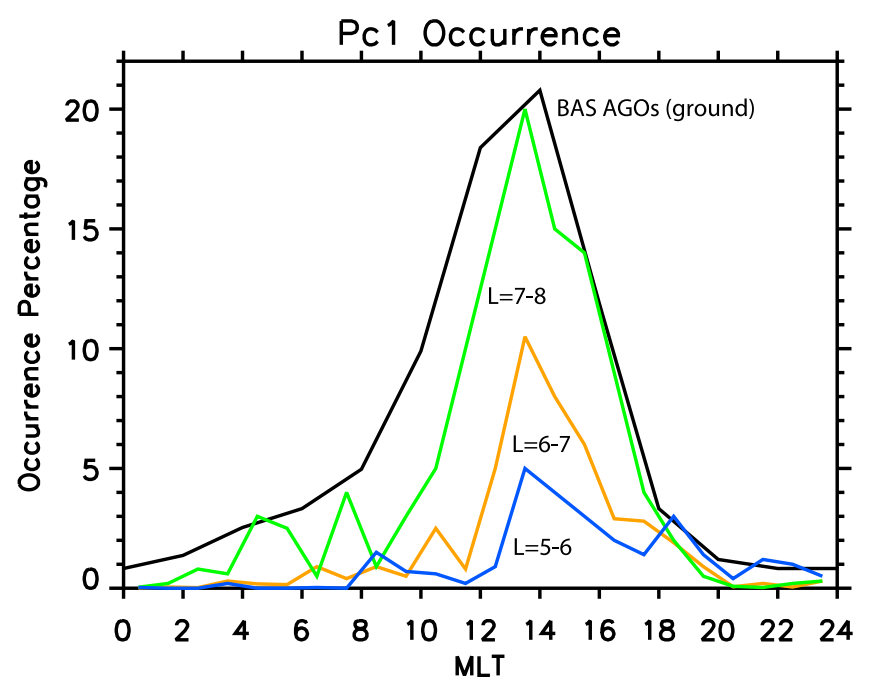

Figure 11. Comparison of the Pc1 occurrence percentages observed by the equatorially orbiting Active Magnetospheric Particle Tracer Explorers/Charge Composition Explorer (AMPTE/CCE) satellite in three $L$ ranges (5-6, 6-7, and 7-8) during one complete pass through all local times from mid 1984 to late 1985 [Anderson et al., 1992a, $1992 \mathrm{~b}]$ and by the BAS AGOs at auroral-zone latitudes from 1996 through 2003.

sharp dropout on the nightside was evident after the start of convection associated with HSSs following disturbed conditions, but was not as clear for HSS events following periods of calm. Contrasting pre- and poststorm activity levels were also observed for HSS events that were calm versus disturbed before onset.

[42] At the auroral latitudes used in this study, Pc1 waves were observed on the ground roughly as often prior to magnetic storms as during storm recovery phase (more often, for the McPherron storm list and for HSS intervals preceded by noise). For each category, Pc1 waves occurred with a high probability at storm onset, SSC onset, or HSS onset, with a decreasing probability during the main phase, and with the lowest probability during the early recovery phase for each storm category.

[43] Finally, auroral-zone Pc1 wave occurrences were only loosely related to occurrences of plasmaspheric plumes and regions of high cold-plasma density at geosynchronous orbit during most phases of these events. Although there was some diurnal overlap in individual cases, plumes generally occurred at later LTs, and often peaked in occurrence 2-4 h after peaks of wave occurrence.

\section{Discussion}

[44] Although the focus of this study is the relation between Pc1 waves and the occurrence of plasmaspheric plumes or related enhancements of cold-plasma density, we first consider the diurnal and storm-time occurrence pattern of $\mathrm{Pc} 1$ waves in this data set.

\subsection{Diurnal Patterns of Pc1 Occurrence}

[45] Pc1 waves observed at ground stations at auroral-zone latitudes occurred predominantly during noon-postnoon hours during all phases of magnetic storms, SSCs, and HSS impacts. This diurnal pattern is consistent with an earlier ground-based study by Popecki et al. [1993], which used a full year of data from Antarctic stations from $L=4$ to $L \sim 15$ (their Figure 4), and with the AMPTE/CCE observations of Anderson et al. [1992a, 1992b] in the equatorial outer magnetosphere. Both of these earlier studies compiled their diurnal distributions without consideration of storm phases. Figure 11, adapted from Figure 12 of Anderson et al. [1992a], shows the LT distribution of Pc1 waves in space observed by the equatorially orbiting AMPTE/CCE satellite from day 239 of 1984 through day 326 of 1985 (covering one complete cycle in LT) for three ranges of $L(5-6,6-7$, and $7-8)$ and the occurrence rate for all events identified in the 8 years of this study. (As noted in section 2, most of the Pc1 events observed by Anderson et al. [1992a] beyond $L=6$ at all LTs were at frequencies of $\leq 1 \mathrm{~Hz}$, so these data sets are in fact comparable.) For each $L$ range the Pc1 occurrence rate observed in space peaked between 1300 and 1400 MLT. The Pc1 activity reported in this study peaked in the 1600-1800 UT bin, which corresponds to 1300-1500 MLT.

[46] Figure 11 also shows that the Pcl occurrence rate observed at the BAS AGOs exceeded the rate observed by AMPTE/CCE near the geomagnetic equator in both the $L=$ 6-7 and the $L=7-8$ bins. Mursula et al. [1996] similarly found that overall Pc1 occurrence rates were higher at Sodankylä, Finland $(L=5.1)$ than at AMPTE/CCE during its passes over Finland. Although these comparisons might be considered surprising, based on the expectation that some EMIC wave signals would be reflected or absorbed before they could reach the ground, it overlooks the fact, as Mursula et al. [1996] noted, that waves might reach a given ground station via ducting in the ionospheric waveguide from source field lines at different longitudes or $L$-shells.

[47] The LT occurrence pattern of Pc1 waves presented here differs somewhat from that at subauroral latitudes at Halley, Antarctica, at $L=4.2$ (Figure 6 of Engebretson et al. [2008a]). At Halley the LT distribution showed an afternoon peak in the first 2 days of the recovery period but was roughly uniform in LT thereafter. The Anderson et al. [1992a] diurnal patterns for $L<6$ (not shown) are roughly consistent with the Halley results. The auroral-zone patterns presented here differ even more from the occurrence pattern reported by Bortnik et al. [2008] at Parkside, California $(L=$ 1.77), where Pc1 waves exhibited a strong diurnal occurrence maximum during nighttime hours during all storm phases.

\subsection{Pc1 Occurrence During the Main Phase and Early Recovery Phase}

[48] There has been conflicting evidence regarding whether Pc1 events occur often during the main phase and whether, if they do, they might not appear in ground records [see, e.g., Engebretson et al., 2008a, 2008b]. Bräysy et al. [1998] found Pc1 events in Freja satellite data during the main phase of a great magnetic storm but no events at conjugate ground stations. Engebretson et al. [2008b], using ST5 satellite data in a similar orbit, found no main phase Pc1 events during several modest storms in 2006. Erlandson and Ukhorskiy [2001] found a number of main-phase events in a statistical study of DE-1 satellite data but noted that one 


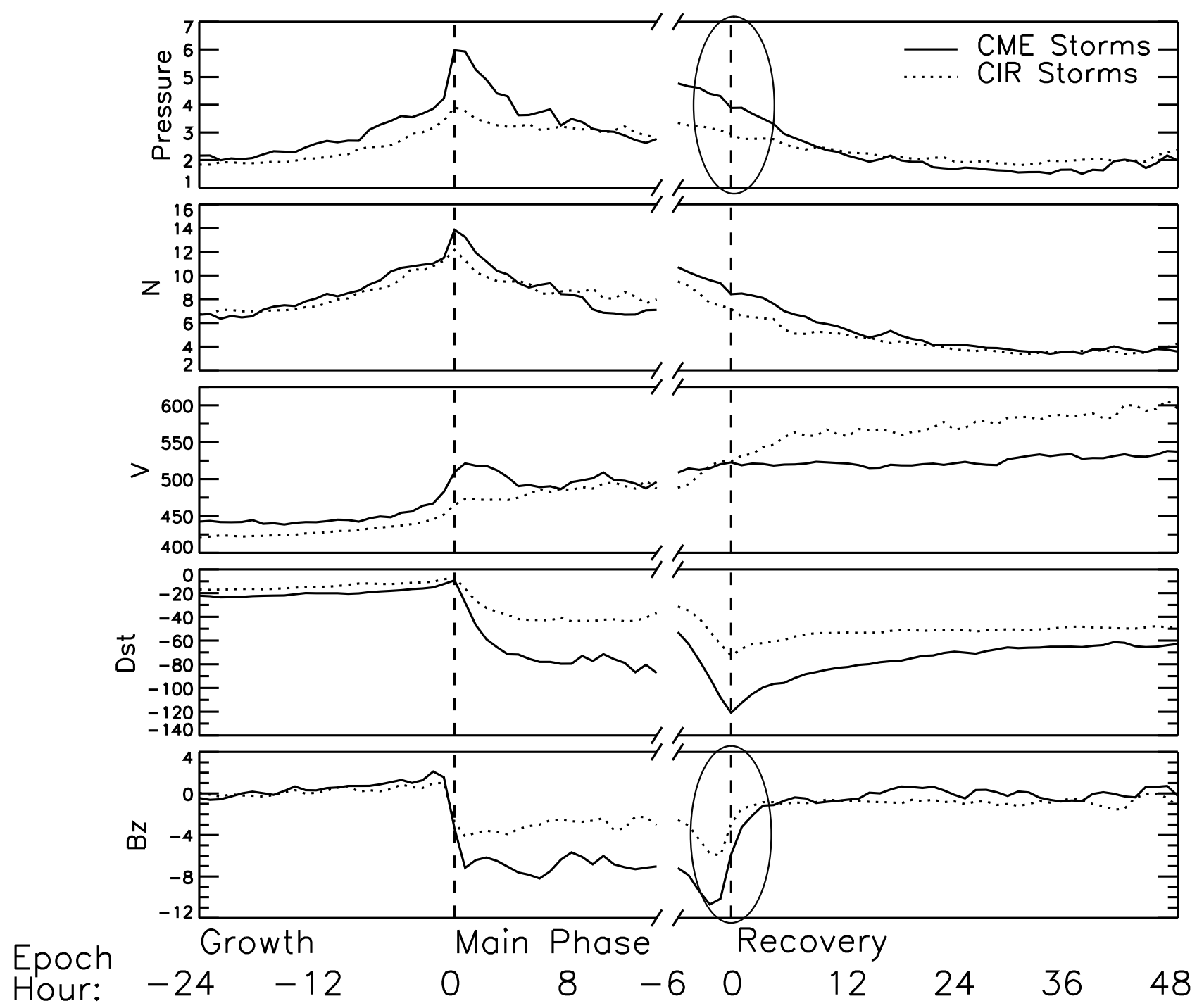

Figure 12. Superposed epoch plots of the solar wind pressure $(\mathrm{nPa})$, solar wind density $\left(N ; \mathrm{cm}^{-3}\right)$, solar wind velocity $(V ; \mathrm{km} / \mathrm{s}), D s t$ index, and $z$ component of the interplanetary magnetic field $(B z ; \mathrm{nT})$, for 169 coronal mass ejection (CME) storms and 208 corotating interaction region (CIR) storms between 1991 and 2004 [Simms et al., 2010]. Using the first drop in Dst as the marker between the onset and the main phase, and the lowest value of Dst as the marker between the main phase and recovery, hourly data for CME and CIR storms were averaged and plotted.

large storm contributed 21 of the 22 events recorded. Most recently, Fraser et al. [2010], using GOES 8, 9, and 10 magnetometer data at geosynchronous orbit from 1996 through 2003, found EMIC waves during 13 of the 20 storms studied. The data presented here also suggest that $\mathrm{Pcl}$ events do occur in auroral-zone ground records during the main phase of some storms, but with an occurrence rate lower than prestorm values.

[49] The relative absence of Pc1 waves in ground records during the early recovery phase may be due to poor propagation conditions (increased levels of heavy ions and screening by broadband noise, as reviewed by Engebretson et al. [2008a]) but may also truly reflect an occurrence minimum. Such a minimum is consistent with the decrease in solar wind pressure often seen at this time [Kataoka and Miyoshi, 2008; Simms et al., 2010]. Figure 12, adapted from Simms et al. [2010], shows that for both corotating inter- action region (CIR) and coronal mass ejection (CME) storms, there is, on average, (a) a continuing drop in solar wind pressure through the end of the storm main phase and into the early recovery phase and (b) a rapid relaxation of inner magnetospheric convection (the interplanetary magnetic field $B z$ moves northward sharply) at the end of the main phase. Both of these effects will act to reduce the occurrence and/or the intensity of magnetospheric electromagnetic ion cyclotron wave activity.

\subsection{The Role of Magnetospheric Compressions}

[50] The examples shown in Figures 3 and 4 and the relatively poor statistical coincidence between Pcl waves and occurrences of plasmaspheric plumes and associated increased densities of cold plasma suggest that other factors must play a major role in stimulating these waves. Indeed, it is well known that pressure anisotropy of ring current ions 
excites EMIC waves, provided their density is sufficiently high. A high-density plume (or extended plasmasphere) reduces the resonant energy, but as this study shows, waves are observed outside the plumes, so a high density is not required in the outer magnetosphere for wave generation. We reiterate that this observational result is consistent with the recent theoretical study by Chen et al. [2009], which found that strong wave growth was expected even in the low-density trough region.

[51] In addition, dayside magnetospheric compressions of the kind shown in Figures 3 and 4 occur frequently and are well-known triggers for Pc1 waves [Olson and Lee, 1983; Anderson and Hamilton, 1993; Kangas et al., 1998; Engebretson et al., 2002; Arnoldy et al., 2005]. Groundbased studies of Pc1 waves triggered by sudden impulses [Olson and Lee, 1983; Kangas et al., 1986] were followed by observational studies by Anderson and Hamilton [1993], who found that, among isolated sudden ( $<5 \mathrm{~min})$ magnetic field increases of $\geq 10 \mathrm{nT}$ in the $0800-1600 \mathrm{MLT} / L>6$ region, $47 \%$ were associated with EMIC wave onset at the equatorially orbiting AMPTE/CCE satellite. Engebretson et al. [2002], using Polar satellite data and conjugate Antarctic ground data, found that 15 of the $20 \mathrm{Pc} 1$ events they observed both at Polar and on the ground in the auroral zone in Antarctica during close field line conjunctions over the first 17 months of Polar's operations were associated with compressions. The latter were identified using time-shifted solar wind dynamic pressure data from the upstream Wind spacecraft, local magnetic field data at Polar, and geosynchronous data from the GOES-8 satellite. Ishida et al. [1987], using data from ATS 6 at geosynchronous orbit, also noted that many of the dayside events they observed were correlated with compression-related increases in the strength of the local magnetic field.

[52] Anderson and Hamilton [1993] calculated EMIC growth rates using measured ion and magnetic field data and found increases of up to several orders of magnitude during compressions. They also suggested that compressionassociated enhancements of low- $L$ EMIC waves should be much smaller because of the lower change in the magnetic field. Kangas et al. [1998] estimated that the amplitude threshold $A_{c}$ for sudden-impulse-stimulated growth of Pc1 waves is a decreasing function of $L,\left(\sim L^{-7}\right)$, consistent with the observations of Anderson and Hamilton [1993].

[53] However, compression-related stimulation of Pc1 waves can evidently occur even in the middle magnetosphere. Zolotukhina et al. [2007] reported compressionrelated EMIC waves even at low-latitude ground stations $(L=2.9, L=2.1)$ during the recovery phase of a moderate geomagnetic storm, and Usanova et al. [2008] suggested, based on observations of EMIC waves by the THEMIS satellites and near-conjugate ground stations near 0800 MLT, that solar wind density enhancements may play a role in exciting compression-related EMIC waves even near the plasmapause. McCollough et al. [2009] recently modeled the compression-stimulated wave growth for this latter event and obtained results consistent with what was observed.

\subsection{Plumes and Pc1 Waves}

[54] As noted earlier, a primary motivation for exploring a possible connection between Pc1 waves and plasmaspheric plumes and/or an extended plasmasphere is the possible importance of EMIC waves in these higher density regions for precipitating radiation-belt electrons. Our observations have confirmed that the occurrence of plasmaspheric plumes increases substantially during the main phase as well as the early recovery phase of the several varieties of magnetic storms and related disturbances presented here, but their temporal pattern matches only poorly the temporal pattern of Pcl waves in either UT or MLT. The implication of our observations is thus that while some EMIC waves do occur in the these regions, they are relatively uncommon, and thus plume-related EMIC waves might not be expected to play a major role in depleting the radiation belts during magnetic storms. Consistent with this conclusion, a recent study by Horne et al. [2009], using 9 years of low-altitude observations of precipitating energetic electrons, did not find strong evidence for mega-electron-volt electron precipitation during the storm main phase that could be associated with EMIC waves, but did find evidence for mega-electron-volt electron precipitation that was delayed by a few days from the storm main phase. Similarly, a global kinetic simulation study by Jordanova et al. [2008] showed that pitch angle scattering of EMIC waves is not primary for mega-electronvolt electron loss. This is consistent with the overall temporal pattern of Pc1 wave occurrence found in the BAS AGO search coil magnetometer data presented here and in many earlier studies of Pc1 waves. Figure 10a, however, shows enhanced Pc1 wave and plume occurrence during the first 2 days after the onset of high-speed solar wind streams following calm periods, so the EMIC wave contribution to electron loss may be higher during these events than during other types of events driven by the solar wind.

\section{Summary and Conclusions}

[55] We have found only a modest association between the occurrence of Pcl waves observed on the ground at auroral latitudes and the presence of plasmaspheric plumes at geosynchronous orbit during any phases of geomagnetic storms and sudden commencements, but a better association during the first 2 days after HSS intervals. Although at times Pc1 waves do coincide with intervals of plume occurrence, plumes (or even elevated levels of cold plasma) are evidently not necessary for EMIC wave generation at these $L$ shells, even during storm times. The examples presented here serve as reminders that magnetospheric compressions are also of considerable importance in stimulating these waves, and recent reports (reviewed in section 6.3) suggest their importance not only for the outer magnetosphere, where their effect is well understood, but even at lower $L$ shells, near the plasmapause.

[56] We emphasize that the ground stations used in this study ( $L=6.28-8.07$ ) will be most sensitive to EMIC waves in the outer magnetosphere, which are known to be strongly correlated with magnetospheric compressions. A similar study should be performed using stations at lower $L$ shells to fully understand the relationship between EMIC waves and plasmaspheric plumes during geomagnetic storms.

[57] The diurnal occurrence patterns of Pcl activity in the middle and outer magnetosphere noted by Anderson et al., [1992a, 1992b] are reaffirmed in this study: Pc1 activity is strongly peaked between 1200 and 1600 MLT during all 
storm phases, whereas the peak occurrence of plumes and regions of extended plasmasphere is shifted toward later LTs.

[58] Pc1 waves are most common during the several days prior to magnetic storms or in the late recovery phase, consistent with many earlier studies. They are observed on the ground at times during the main phase, many times in association with increases in solar wind pressure, and least often during the early recovery phase. Future comparisons of in situ data from equatorially orbiting spacecraft and a sufficiently dense array of ground-based instruments capable of detecting the full range of Pc1 waves will be needed to verify whether the relative absence of Pc1 waves in ground records during the early recovery phase is due to poor propagation conditions (increased levels of heavy ions and/or screening by broadband noise) or accurately reflects a reduction in their generation during this storm phase, as well as to fully characterize the propagation of EMIC waves along magnetic field lines from the equatorial regions to higher latitudes, through the ionosphere, and to the ground.

[59] Acknowledgments. We thank Jacob Bortnik of UCLA for providing the wave detection software used in this study and Richard Denton of Dartmouth College for performing the model magnetic field calculations that formed the basis of Table 1. We are also grateful to Mike Rose and the entire engineering and logistics staff at the British Antarctic Survey for their deployment and operation of the BAS AGOs. This research was supported by NSF grants ANT- 0538379 and ANT-0838917 to Augsburg College, by NSF grants ANT-0538474 and ANT-0838910 to the University of New Hampshire, by STFC grant ST/G002401/1 to Lancaster University, and by the Natural Environment Research Council at the British Antarctic Survey.

[60] Masaki Fujimoto thanks Robert E. Erlandson and another reviewer for their assistance in evaluating the manuscript.

\section{References}

Anderson, B. J., and D. C. Hamilton (1993), Electromagnetic ion cyclotron waves stimulated by modest magnetospheric compressions, J. Geophys. Res., 98, 11369-11382.

Anderson, B. J., R. E. Erlandson, and L. J. Zanetti (1992a), A statistical study of Pc1-2 magnetic pulsations in the equatorial magnetosphere: 1. Equatorial occurrence distributions, J. Geophys. Res., 97, 3075-3088.

Anderson, B. J., R. E. Erlandson, and L. J. Zanetti (1992b), A statistical study of Pc1-2 magnetic pulsations in the equatorial magnetosphere: 2. Wave properties, J. Geophys. Res., 97, 3089-3101.

Arnoldy, R. L., M. J. Engebretson, R. E. Denton, J. L. Posch, N. C. Maynard, D. M. Ober, C. J. Farrugia, C. T. Russell, J. D. Scudder, M. R. Lessard, R. B. Torbert, S.-H. Chen, and T. E. Moore (2005), Pc1 waves and associated unstable distributions of magnetospheric protons observed during a solar wind pressure pulse, J. Geophys. Res., 110, A07229, doi:10.1029/2005JA011041.

Borovsky, J. E., and M. H. Denton (2008), A statistical look at plasmaspheric drainage plumes, J. Geophys. Res., 113, A09221, doi:10.1029/ 2007JA012994.

Borovsky, J. E., and M. H. Denton (2009), Relativistic electron dropouts and recovery: A superposed-epoch study of the magnetosphere and the solar wind, J. Geophys. Res., 114, A02201, doi:10.1029/2008JA013128.

Bortnik, J., J. W. Cutler, C. Dunson, and T. E. Bleier (2007), An automatic wave detection algorithm applied to $\mathrm{Pc1}$ pulsations, J. Geophys. Res., 112, A04204, doi:10.1029/2006JA011900.

Bortnik, J., J. W. Cutler, C. Dunson, T. E. Bleier, and R. L. McPherron (2008), Characteristics of low-latitude Pc1 pulsations during geomagnetic storms, J. Geophys. Res., 113, A04201, doi:10.1029/ 2007JA012867.

Bräysy, T., K. Mursula, and G. Marklund (1998), Ion cyclotron waves during a great magnetic storm observed by Freja double-probe electric field instrument, J. Geophys. Res., 103, 4145-1455, doi:10.1029/97JA02820.

Burch, J. L., D. G. Mitchell, B. R. Sandel, P. C. Brandt, and M. Wuest (2001), Global dynamics of the plasmasphere and ring current during magnetic storms, Geophys. Res. Lett., 28, 1159-1162.

Chen, L., R. M. Thorne, and R. B. Horne (2009), Simulation of EMIC wave excitation in a model magnetosphere including structured high- density plumes, J. Geophys. Res., 114, A07221, doi:10.1029/ 2009JA014204.

Clilverd, M. A., C. J. Rodger, R. M. Millan, J. G. Sample, M. Kokorowski, M. P. McCarthy, T. Ulich, T. Raita, A. J. Kavanagh, and E. Spanswick (2007), Energetic particle precipitation into the middle atmosphere triggered by a coronal mass ejection, J. Geophys. Res., 112, A12206, doi:10.1029/2007JA012395.

Denton, M. H., and J. E. Borovsky (2008), Superposed epoch analysis of high-speed stream effects at geosynchronous orbit: Hot plasma, cold plasma, and the solar wind, J. Geophys. Res., 113, A07216, doi:10.1029/2007JA012998.

Dudeney, J. R., R. B. Horne, M. J. Jarvis, R. I. Kressman, A. S. Rodger, and A. J. Smith (1997), British Antarctic Survey's ground-based activities complementary to satellite missions such as Cluster, in Satellite-Ground Based Coordination Sourcebook, Eur. Space Agency Spec. Publ ESA $S P-1198$, edited by M. Lockwood, M. N. Wild, and H. J. Opgenoorth, pp. 101-110, European Space Agency, Paris.

Engebretson, M. J., W. K. Peterson, J. L. Posch, M. R. Klatt, B. J. Anderson, C. T. Russell, H. J. Singer, R. L. Arnoldy, and H. Fukunishi (2002), Observations of two types of Pc1-2 pulsations in the outer dayside magnetosphere, J. Geophys. Res., 107(A12), 1451, doi:10.1029/ 2001JA000198.

Engebretson, M. J., A. Keiling, K.-H. Fornacon, C. A. Cattell, J. R. Johnson, J. L. Posch, S. R. Quick, K.-H. Glassmeier, G. K. Parks, and H. Rème (2007), Cluster observations of Pc1-2 waves and associated ion distributions during the October and November 2003 magnetic storms, Planet. Space Sci., 55, 829-848, doi:10.1016/j.pss.2006.03.015.

Engebretson, M. J., et al. (2008a), Pc1-Pc2 waves and energetic particle precipitation during and after magnetic storms: Superposed epoch analysis and case studies, J. Geophys. Res., 113, A01211, doi:10.1029/ 2007JA012362.

Engebretson, M. J., J. L. Posch, A. M. Westerman, N. J. Otto, J. A. Slavin, G. Le, R. J. Strangeway, and M. R. Lessard (2008b), Temporal and spatial characteristics of Pc1 waves observed by ST5, J. Geophys. Res., 113, A07206, doi: 10.1029/2008JA013145.

Erlandson, R. E., and A. J. Ukhorskiy (2001), Observations of electromagnetic ion cyclotron waves during geomagnetic storms: Wave occurrence and pitch angle scattering, J. Geophys. Res., 106, 3883-3895, doi:10.1029/2000JA000083.

Fraser, B. J., and T. S. Nguyen (2001), Is the plasmapause a preferred source region of electromagnetic ion cyclotron waves in the magnetosphere?, J. Atmos Sol. Terr. Phys., 63, 1225-1247.

Fraser, B. J., H. J. Singer, M. L. Adrian, D. L. Gallagher, and M. F. Thomsen (2005), The relationship between plasma density structure and EMIC waves at geosynchronous orbit, in Inner Magnetosphere Interactions: New Perspectives from Imaging, Geophys. Monogr. Ser., vol. 159, edited by J. Burch, M. Schulz, and H. Spence, pp. 55-70, AGU, Washington, D. C.

Fraser, B. J., R. S. Grew, S. K. Morley, J. C. Green, H. J. Singer, T. M. Loto'aniu, and M. F. Thomsen (2010), Storm time observations of electromagnetic ion cyclotron waves at geosynchronous orbit: GOES results, J. Geophys. Res., 115, A05208, doi:10.1029/2009JA014516.

Fuselier, S. A., S. P. Gary, M. F. Thomsen, E. S. Claflin, B. Hubert, B. R. Sandel, and T. Immel (2004), Generation of transient dayside subauroral proton precipitation, J. Geophys. Res., 109, A12227, doi:10.1029/ 2004JA010393.

Horne, R. B., and R. M. Thorne (1993), On the preferred source location for the convective amplification of ion cyclotron waves, J. Geophys. Res., 98, 9233-9247.

Horne, R. B., M. M. Lam, and J. C. Green (2009), Energetic electron precipitation from the outer radiation belt during geomagnetic storms, Geophys. Res. Lett., 36, L19104, doi:10.1029/2009GL040236.

Hu, Y. D., and B. J. Fraser (1994), Electromagnetic ion cyclotron wave amplification and source regions in the magnetosphere, J. Geophys. Res., 99, 263-272.

Immel, T. J., S. B. Mende, H. U. Frey, J. Patel, J. W. Bonnell, M. J. Engebretson, and S. A. Fuselier (2005), ULF waves associated with enhanced subauroral proton precipitation, in Inner Magnetosphere Interactions: New Perspectives from Imaging, Geophys. Monogr. Ser., vol. 159, edited by J. Burch, M. Schulz, and H. Spence, pp. 71-84, AGU, Washington, D. C.

Ishida, J., S. Kokubun, and R. L. McPherron (1987), Substorm effects on spectral structures of Pc1 waves at synchronous orbit, J. Geophys. Res., 92, 143-158.

Jordanova, V. K., J. Albert, and Y. Miyoshi (2008), Relativistic electron precipitation by EMIC waves from self-consistent global simulations, J. Geophys. Res., 113, A00A10, doi:10.1029/2008JA013239.

Kangas, J., A. Aikio, and J. V. Olson (1986), Multistation correlation spectra associated with sudden impulses, Planet. Space Sci., 34, 543-553. 
Kangas, J., A. Guglielmi, and O. Pokhotelov (1998), Morphology and physics of short-period geomagnetic pulsations, Space. Sci. Rev., 83 , 435-512, doi:10.1023/A:1005063911643.

Kataoka, R., and Y. Miyoshi (2008), Magnetosphere inflation during the recovery phase of geomagnetic storms as an excellent magnetic confinement of killer electrons, Geophys. Res. Lett., 35, L06S09, doi:10.1029/ 2007GL031842.

McCollough, J. P., S. R. Elkington, and D. N. Baker (2009), Modeling EMIC wave growth during the compression event of 29 June 2007, Geophys. Res. Lett., 36, L18108, doi:10.1029/2009GL039985.

McPherron, R. L., and J. Weygand (2006), The solar wind and geomagnetic activity as a function of time relative to corotating interaction regions, in Recurrent Magnetic Storms, edited by B. Tsurutani et al., p. 125, AGU, Washington, D. C.

Meredith, N. P., R. M. Thorne, R. B. Horne, D. Summers, B. J. Fraser, and R. R. Anderson (2003), Statistical analysis of relativistic electron energies for cyclotron resonance with EMIC waves observed on CRRES J. Geophys. Res., 108(A6), 1250, doi:10.1029/2002JA009700.

Miyoshi, Y., K. Sakaguchi, K. Shiokawa, D. Evans, J. Albert, M. Connors, and V. Jordanova (2008), Precipitation of radiation belt electrons by EMIC waves, observed from ground and space, Geophys. Res. Lett., 35, L23101, doi:10.1029/2008GL035727.

Mursula, K., J. Kangas, and T. Pikkarainen (1994), Properties of structured and unstructure Pc1 pulsations at high latitudes: Variation over the 21st solar cycle, in Solar Wind Sources of Magnetospheric UltraLow-Frequency Waves, Geophysical Monograph 81, edited by M. J. Engebretson, K. Takahashi, and M. Scholer, pp. 409-415, AGU, Washington, D. C

Mursula, K., B. J. Anderson, R. E. Erlandson, and T. Pikkarainen (1996) Solar cycle change of Pc1 waves observed by an equatorial satellite and on the ground, Adv. Space Res., 17(10), 51-55.

Olson, J. V., and L. C. Lee (1983), Pc1 wave generation by sudden impulses, Planet. Space Sci., 31, 295-302.

Popecki, M., R. Arnoldy, M. J. Engebretson, and L. J. Cahill Jr. (1993), High-latitude ground observations of Pc1/2 micropulsations, J. Geophys. Res., 98, 21,481-21,491.

Rodger, C. J., T. Raita, M. A. Clilverd, A. Seppälä, S. Dietrich, N. R. Thomson, and T. Ulich (2008), Observations of relativistic electron precipitation from the radiation belts driven by EMIC waves, Geophys. Res. Lett., 35, L16106, doi:10.1029/2008GL034804.

Sandanger, M., F. Søraas, K. Aarsnes, K. Oksavik, and D. S. Evans (2007), Loss of relativistic electrons: Evidence for pitch angle scattering by electromagnetic ion cyclotron waves excited by unstable ring current protons, J. Geophys. Res., 112, A12213, doi:10.1029/2006JA012138.
Sandel, B. R., R. A. King, W. T. Forrester, D. L. Gallagher, A. L. Broadfoot, and C. C. Curtis (2001), Initial results from the IMAGE extreme ultraviolet imager, Geophys. Res. Lett., 28, 1439-1442.

Simms, L. E., V. Pilipenko, and M. J. Engebretson (2010), Determining the key drivers of Magnetospheric Pc5 Wave Power, J. Geophys. Res., doi: 10.1029/2009JA015025, in press.

Spasojevíc, M., H. U. Frey, M. F. Thomsen, S. A. Fuselier, B. R. Sandel, and U. S. Inan (2004), The link between a detached subauroral proton arc and a plasmaspheric plume, Geophys. Res. Lett., 31, L04803, doi:10.1029/2003GL018389.

Summers, D., and R. M. Thorne (2003), Relativistic electron pitch-angle scattering by electromagnetic ion cyclotron waves during geomagnetic storms, J. Geophys. Res., 108(A4), 1143, doi:10.1029/2002JA009489.

Thorne, R. M., R. B. Horne, S. A. Glauert, N. P. Meredith, Y. Y. Shprits, D. Summers, and R. R. Anderson (2005), The influence of wave-particle interactions on relativistic electron dynamics during storms, in Inner Magnetosphere Interactions: New Perspectives from Imaging, Geophys. Monogr. Ser., vol. 159, edited by J. L. Burch, M. Schulz, and H. Spence, pp 101-112, AGU, Washington, D. C.

Tsyganenko, N. A. (1989), A magnetospheric magnetic field model with a warped tail current sheet, Planet. Space Sci., 37, 5-20.

Usanova, M. E., I. R. Mann, I. J. Rae, Z. C. Kale, V. Angelopoulos, J. W. Bonnell, K.-H. Glassmeier, H. U. Auster, and H. J. Singer (2008), Multipoint observations of magnetic compression-related EMIC Pc1 waves by THEMIS and CARISMA, Geophys. Res. Lett., 35, L17S25, doi:10.1029/ 2008GL034458.

Zolotukhina, N., V. Pilipenko, M. J. Engebretson, and A. S. Rodger (2007) Response of the inner and outer magnetosphere to solar wind density fluctuations during the recovery phase of a moderate magnetic storm, J. Atmos. Solar Terr. Phys., 69, 1707-1722.

M. H. Denton, Department of Physics, Lancaster University, Lancaster LA1 4WA, UK.

M. J. Engebretson and J. L. Posch (corresponding author), Department of Physics, Augsburg College, 2211 Riverside Ave., Minneapolis, MN 55454 , USA. (posch@augsburg.edu)

R. B. Horne, British Antarctic Survey, Madingley Rd., Cambridge CB3 OET, UK.

M. R. Lessard, Space Science Center and Department of Physics, University of New Hampshire, Durham, NH 03824, USA.

M. T. Murphy, Department of Civil Engineering, University of Minnesota, 500 Pillsbury Dr. S.E., Minneapolis, MN 55455, USA. 